\title{
Route evaluation and Ritter Reaction-Based Synthesis of Oxazoline Acaricide Candidates FET-II-L and NK-12
}

\author{
Yu Zhang, ${ }^{\dagger}$ Shilin Chen, ${ }^{\dagger}$ Yuxiu Liu, ${ }^{*}, \dot{+}$ Qingmin Wang ${ }^{*}, \dot{+},+$ \\ $\uparrow$ State Key Laboratory of Elemento-Organic Chemistry, Research Institute of \\ Elemento-Organic Chemistry, College of Chemistry, Nankai University, Tianjin \\ 300071, People's Republic of China. \\ †Collaborative Innovation Center of Chemical Science and Engineering (Tianjin), \\ Tianjin 300071, People's Republic of China
}

\section{Contents}

${ }^{1} \mathrm{H}$ and ${ }^{13} \mathrm{C}$ NMR Spectra of compounds 9, 11, 12, 13, 4b, 4c, 4d, 15, 17, $19,20,23,5 b, 27,28,29,1,2 \ldots \ldots \ldots \ldots \ldots \ldots \ldots \ldots \ldots \ldots \ldots \ldots \ldots .2$

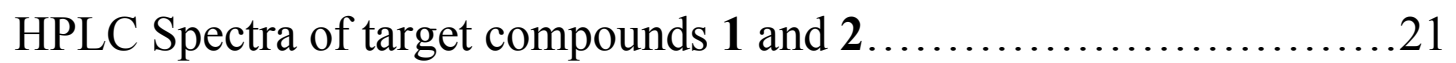




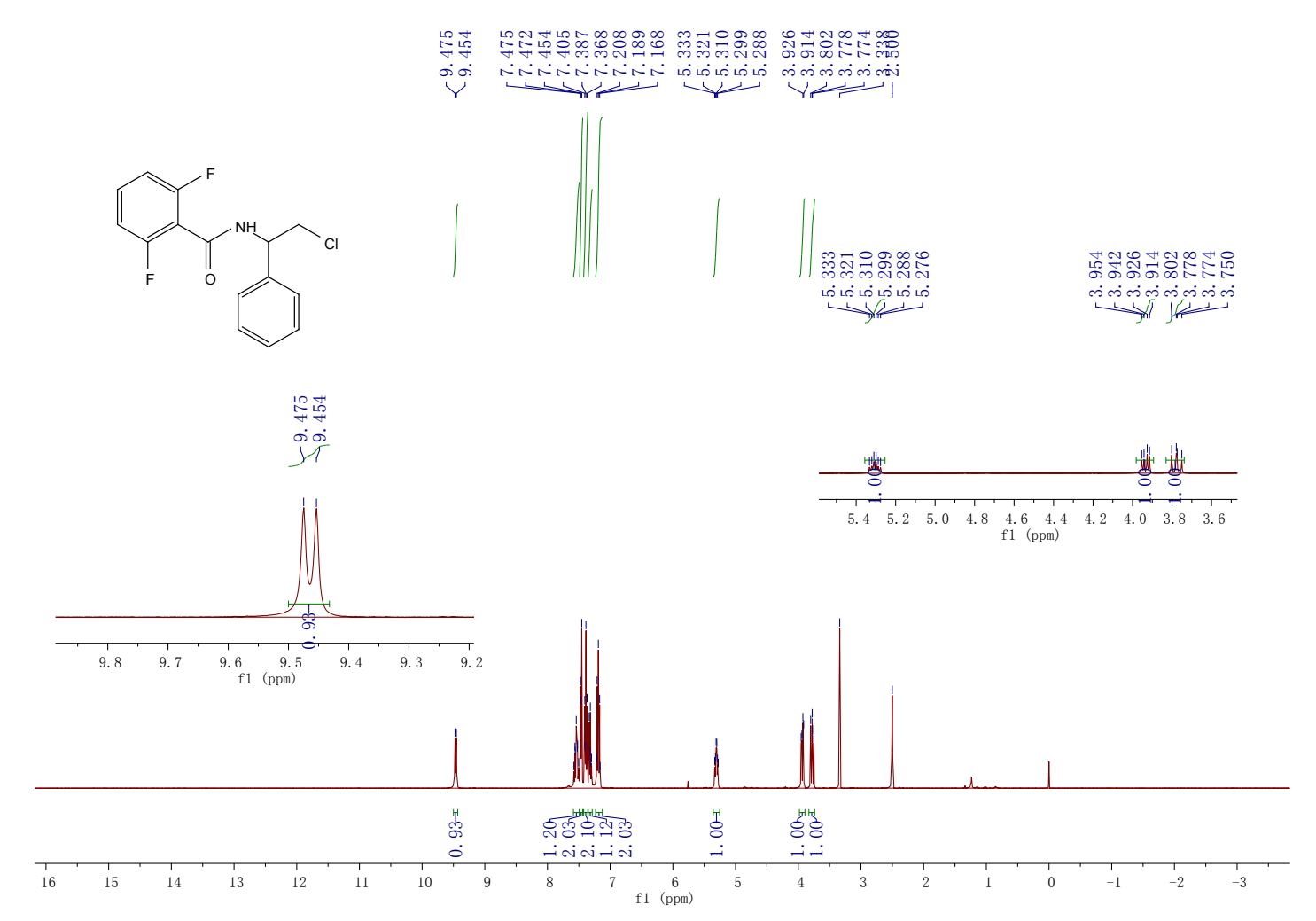

${ }^{1} \mathrm{H}$ NMR of Compound 9

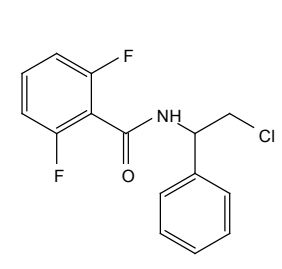

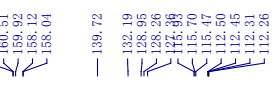

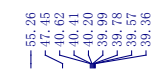

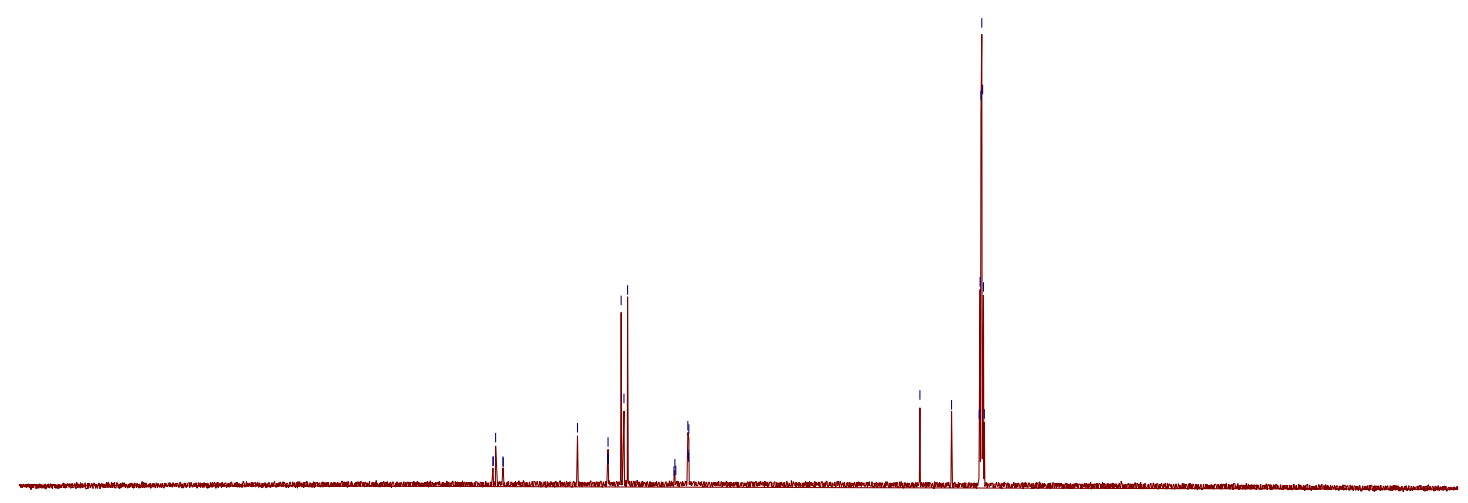

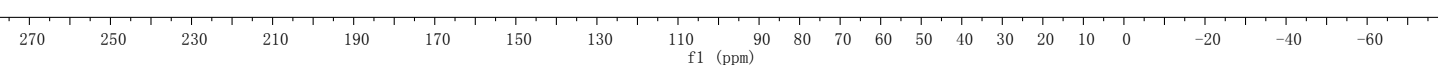

${ }^{13} \mathrm{C}$ NMR of Compound 9 


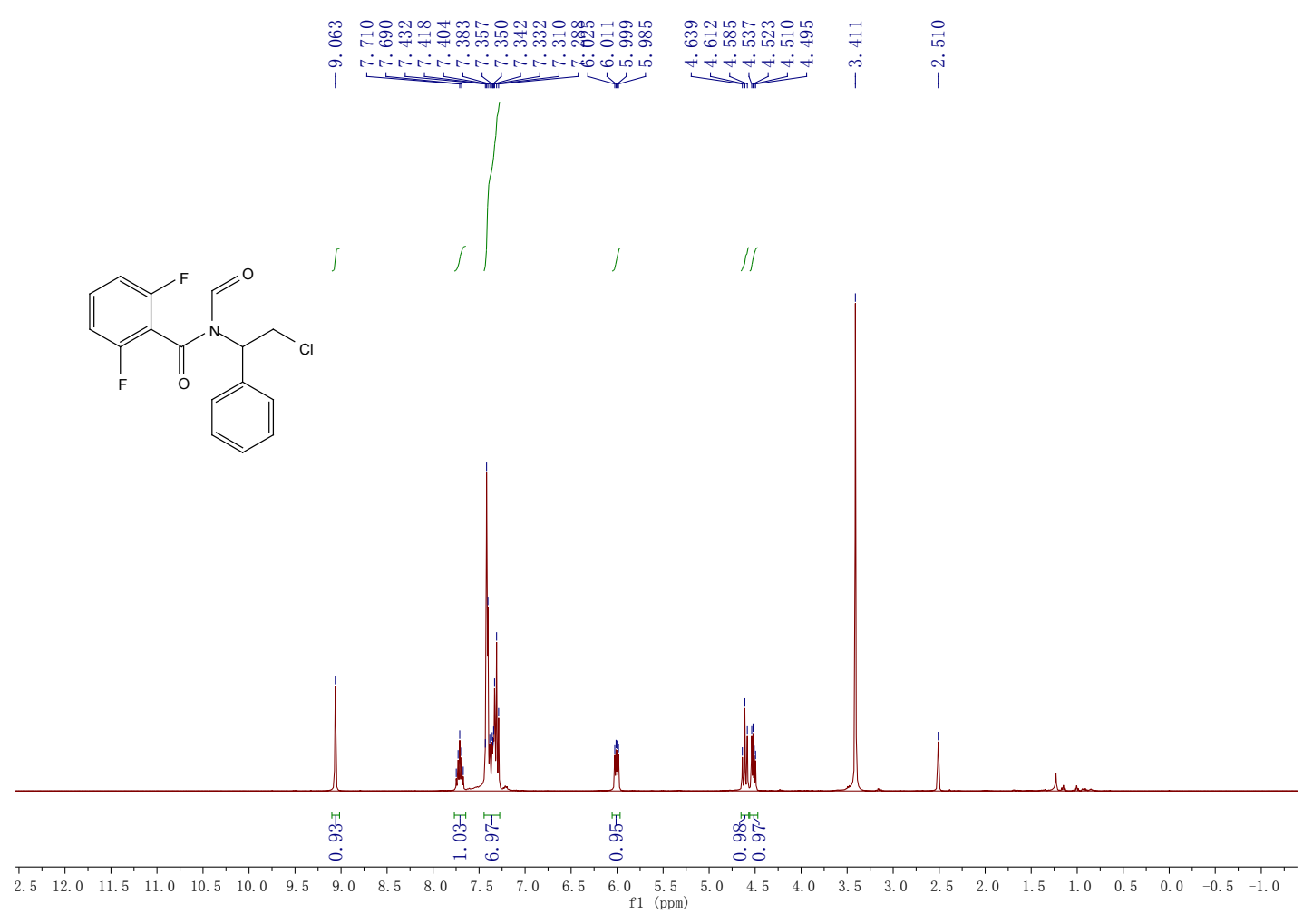

${ }^{1} \mathrm{H}$ NMR of Compound $\mathbf{1 1}$
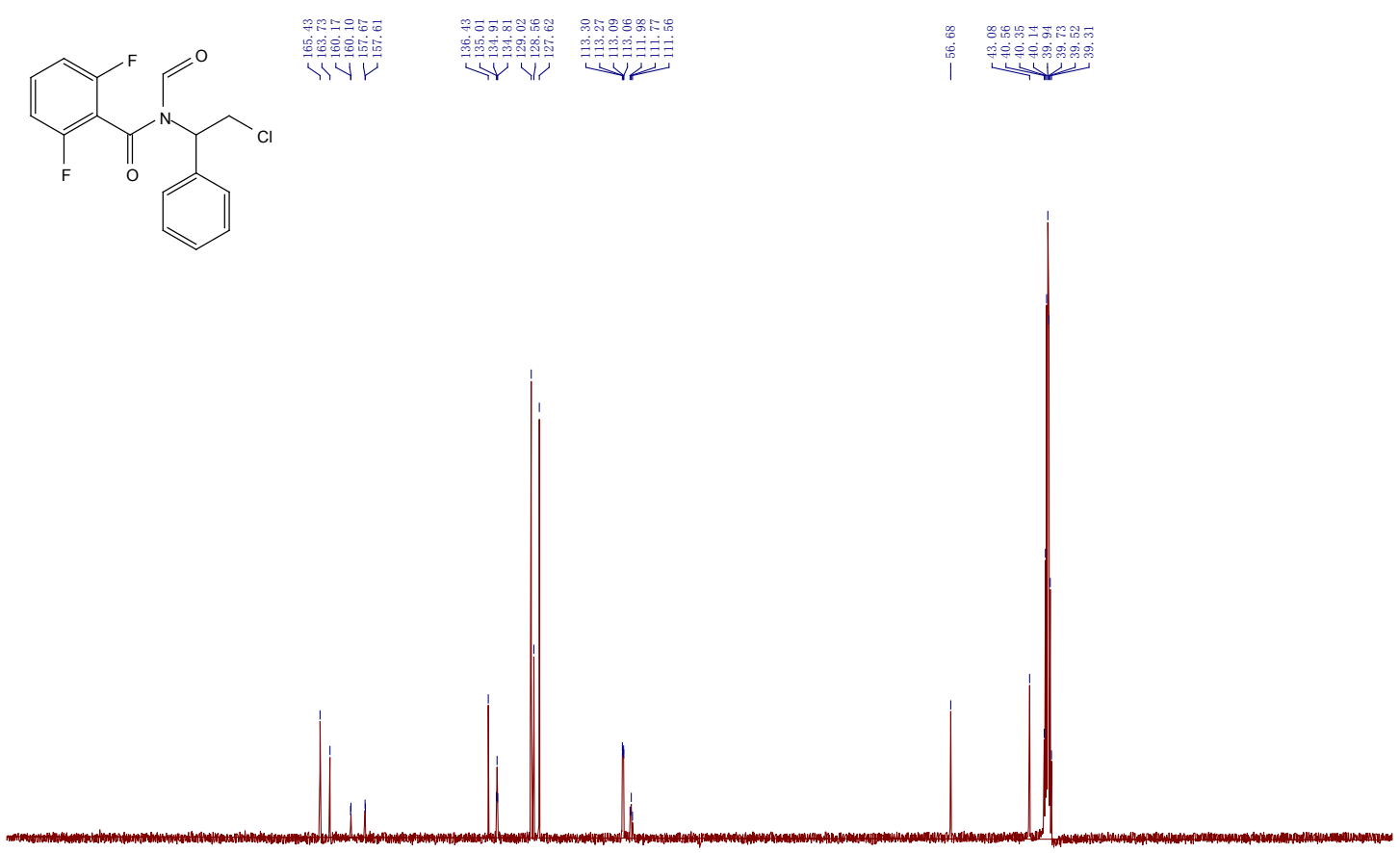

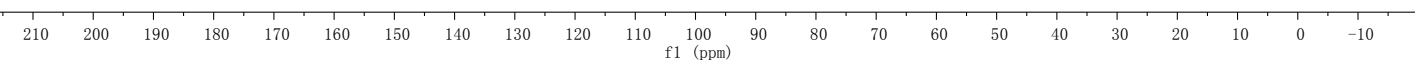

${ }^{13} \mathrm{C}$ NMR of Compound $\mathbf{1 1}$ 


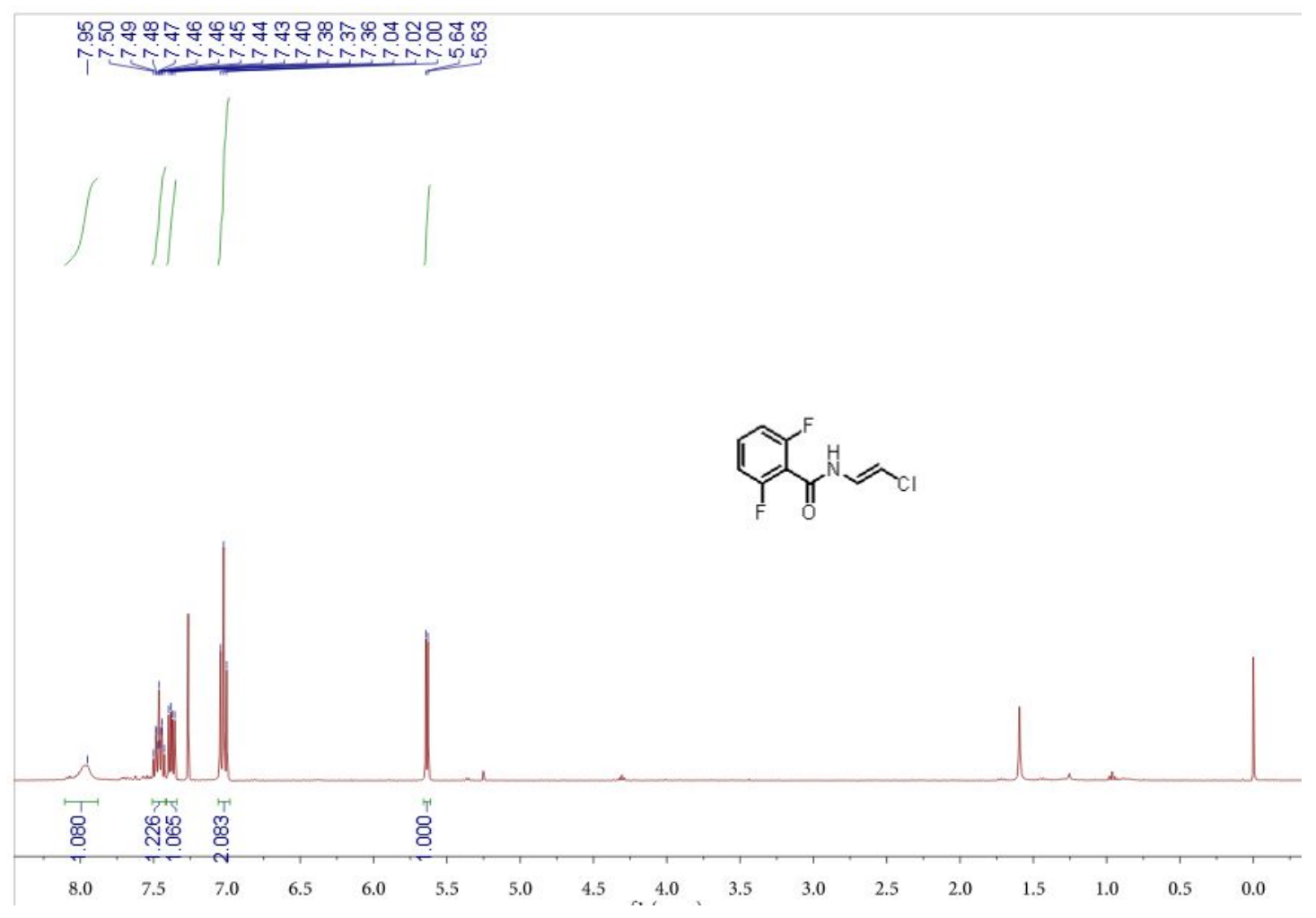

${ }^{1} \mathrm{H}$ NMR of Compound $\mathbf{1 2}$

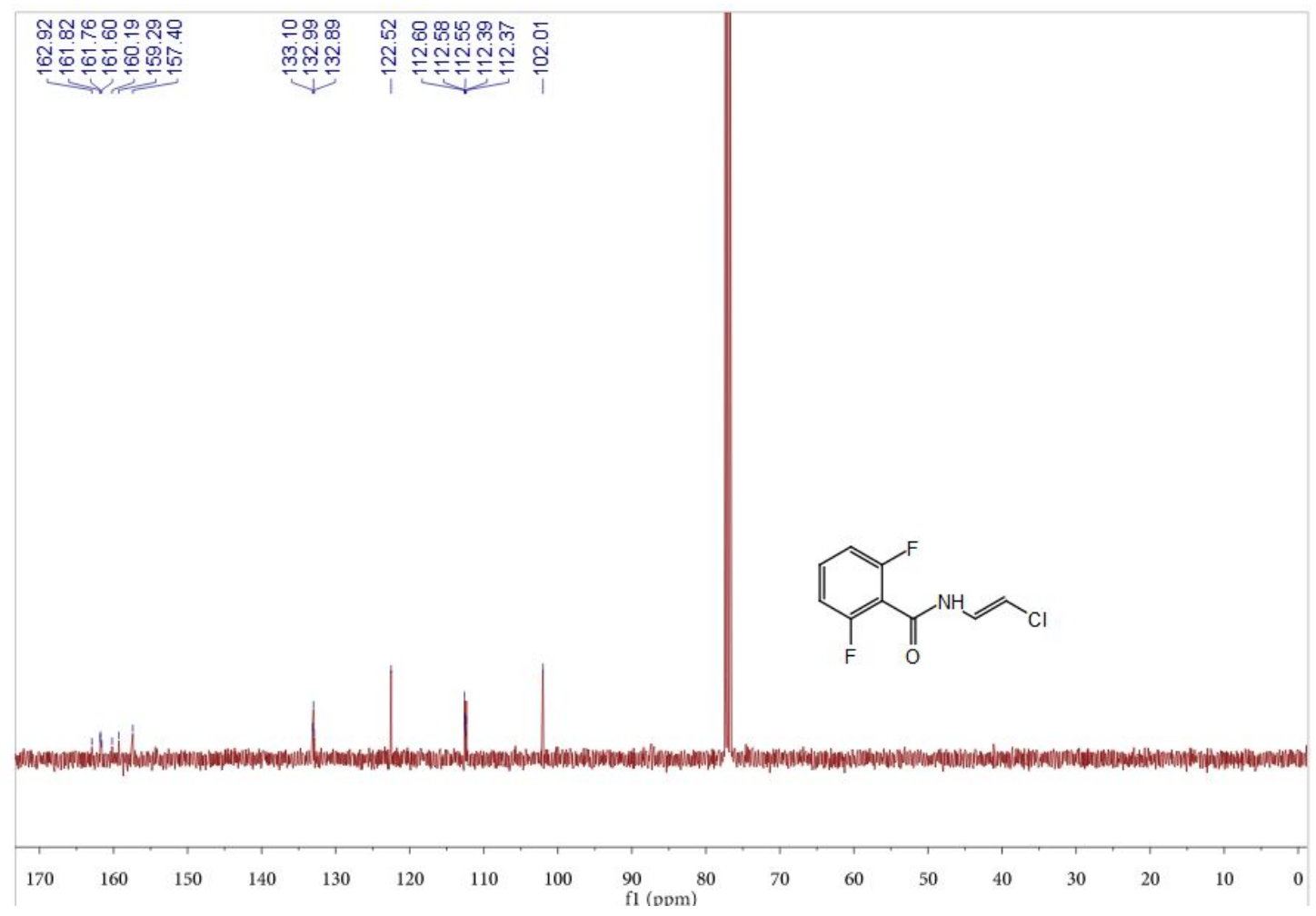

${ }^{13} \mathrm{C}$ NMR of Compound $\mathbf{1 2}$

4 


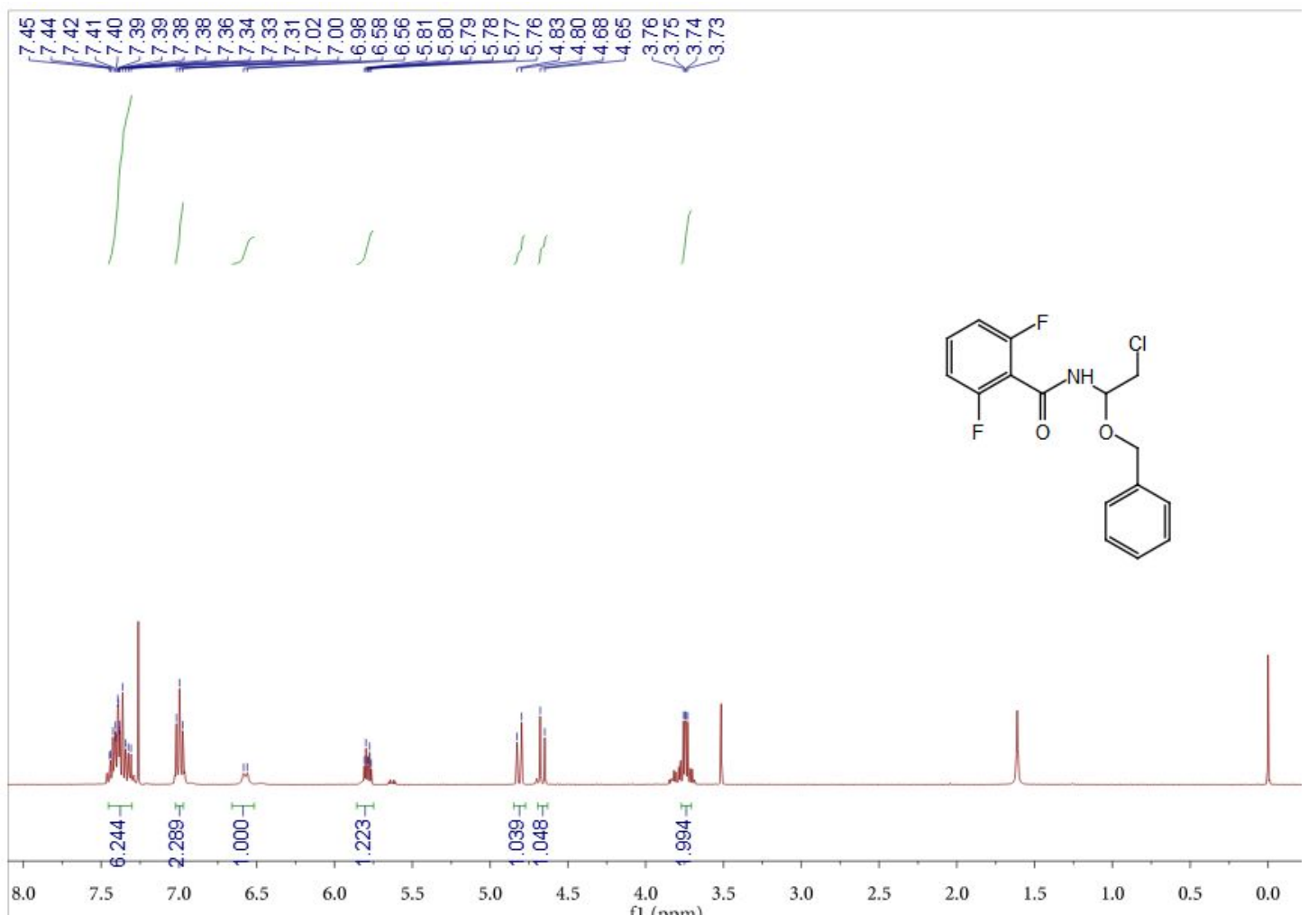

${ }^{1} \mathrm{H}$ NMR of Compound $\mathbf{1 3}$

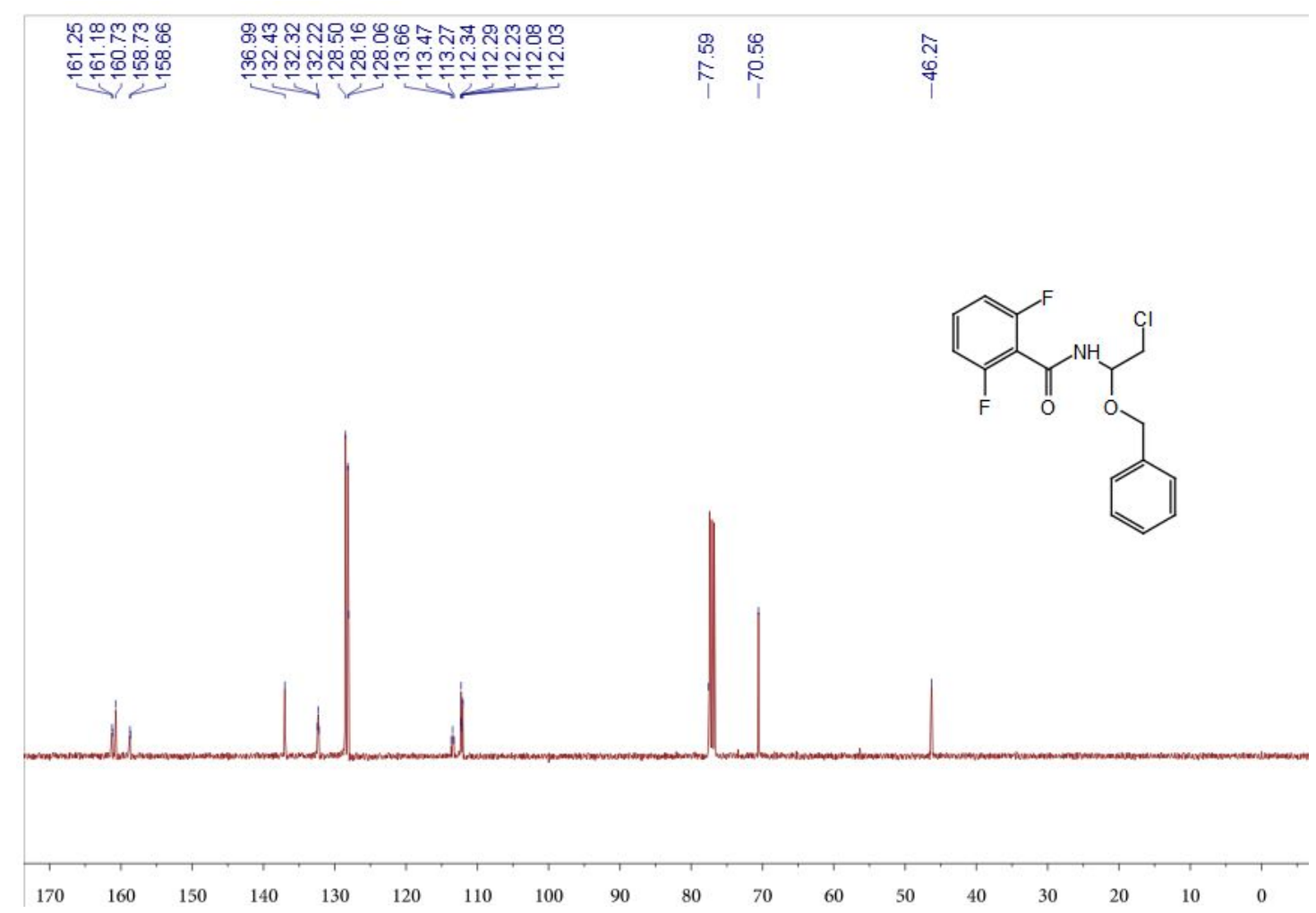

${ }^{13} \mathrm{C}$ NMR of Compound $\mathbf{1 3}$ 


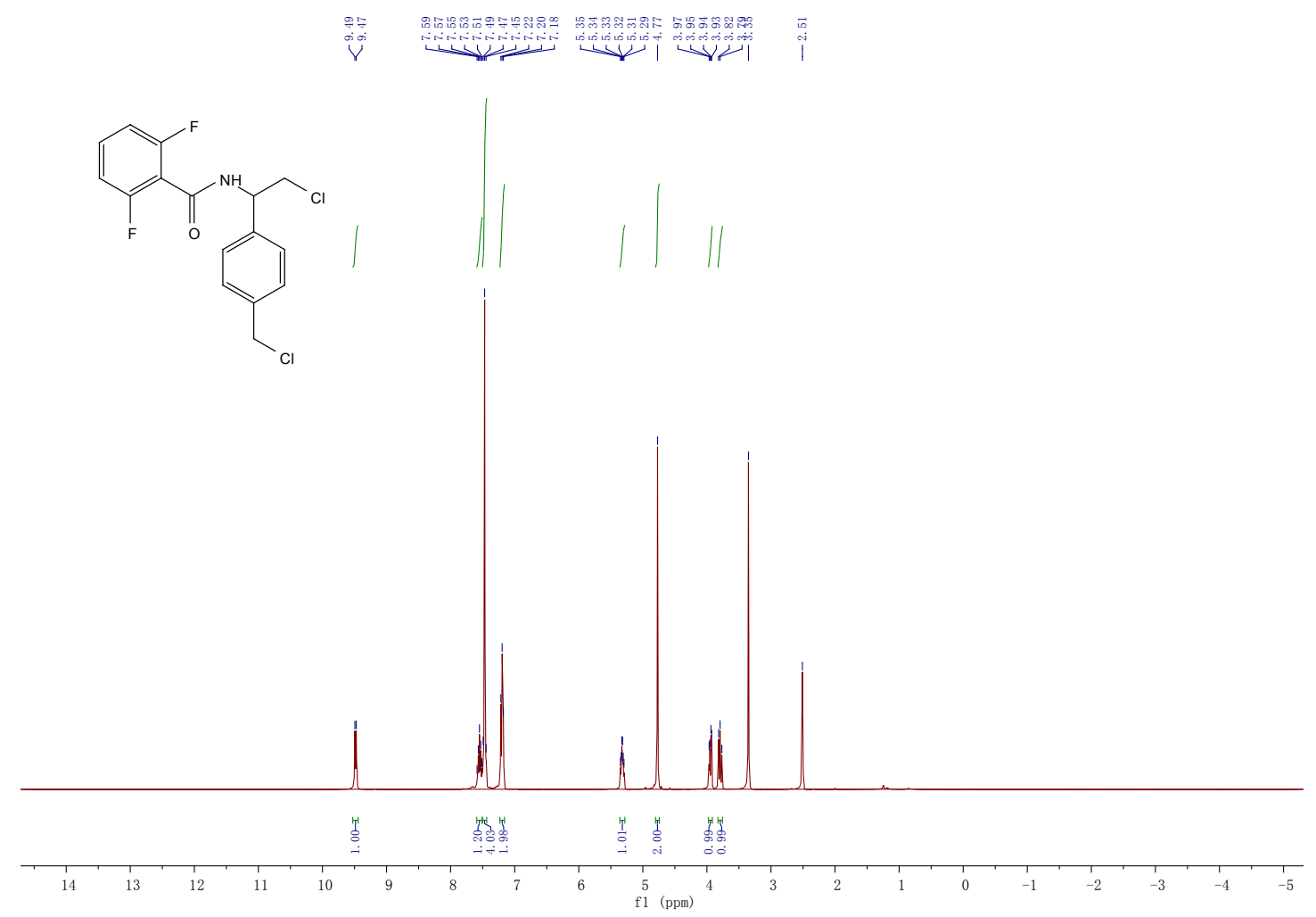

${ }^{1} \mathrm{H}$ NMR of Compound $\mathbf{4 b}$

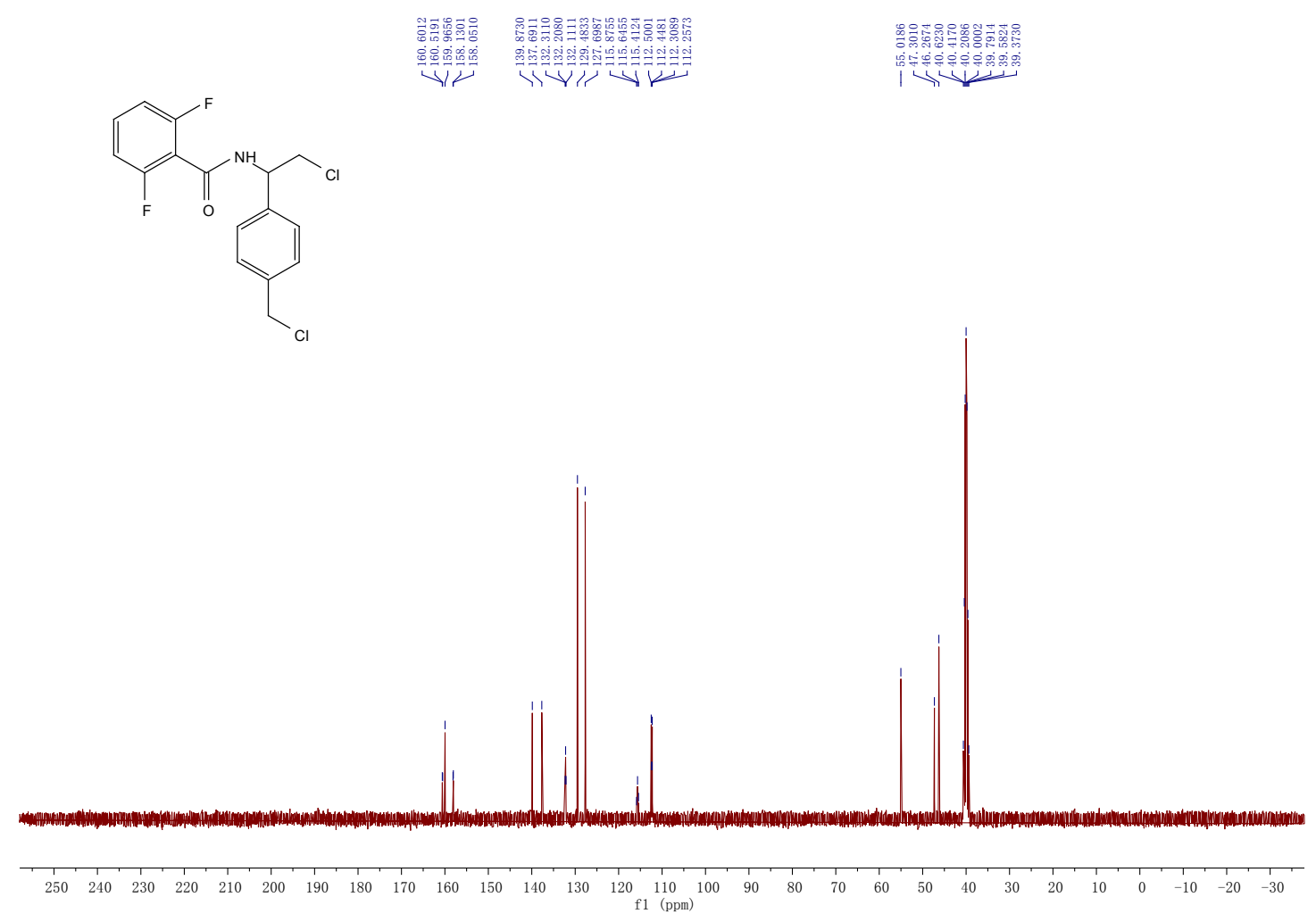

${ }^{13} \mathrm{C}$ NMR of Compound $4 \mathrm{~b}$ 

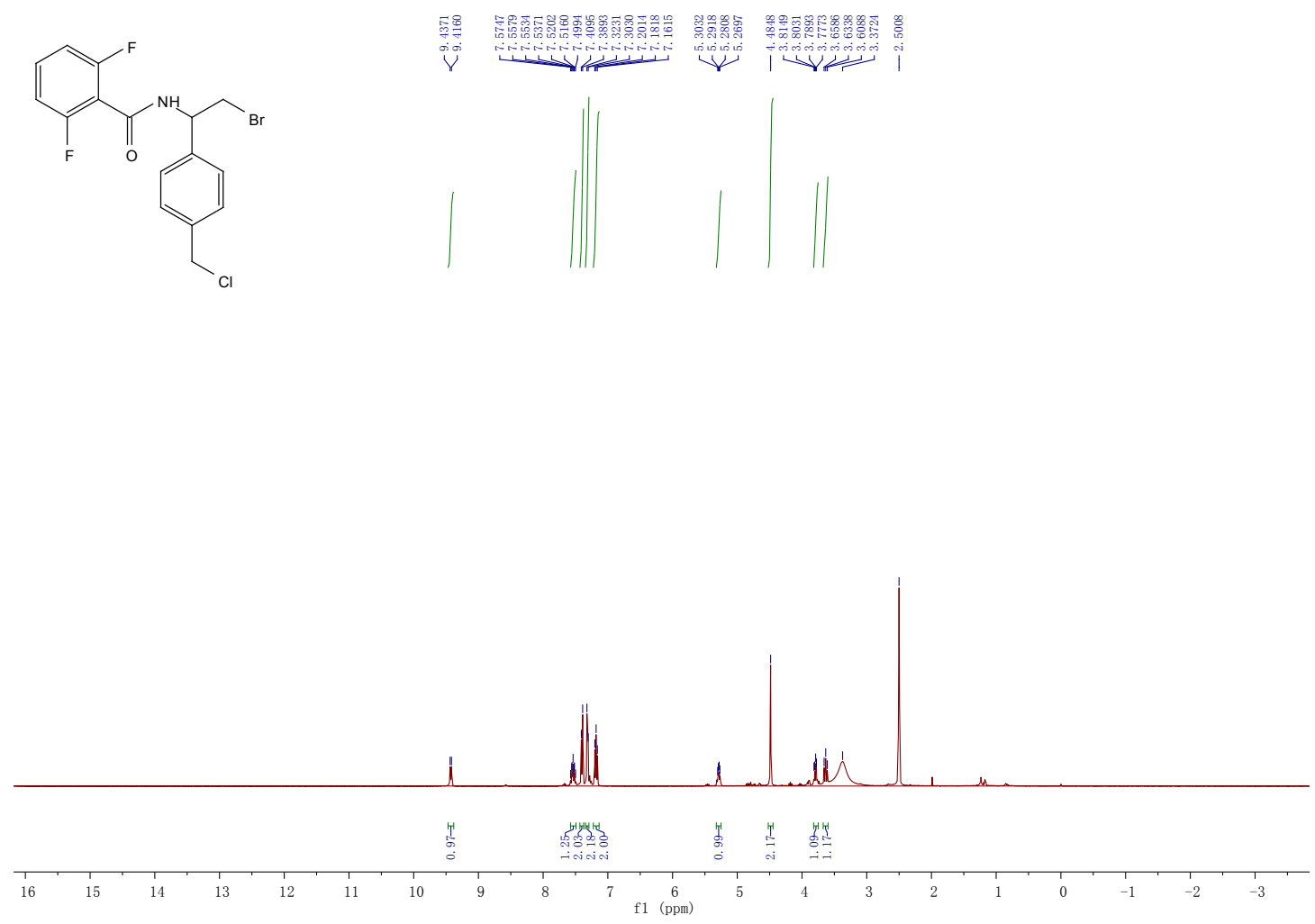

${ }^{1} \mathrm{H}$ NMR of Compound $4 \mathrm{c}$

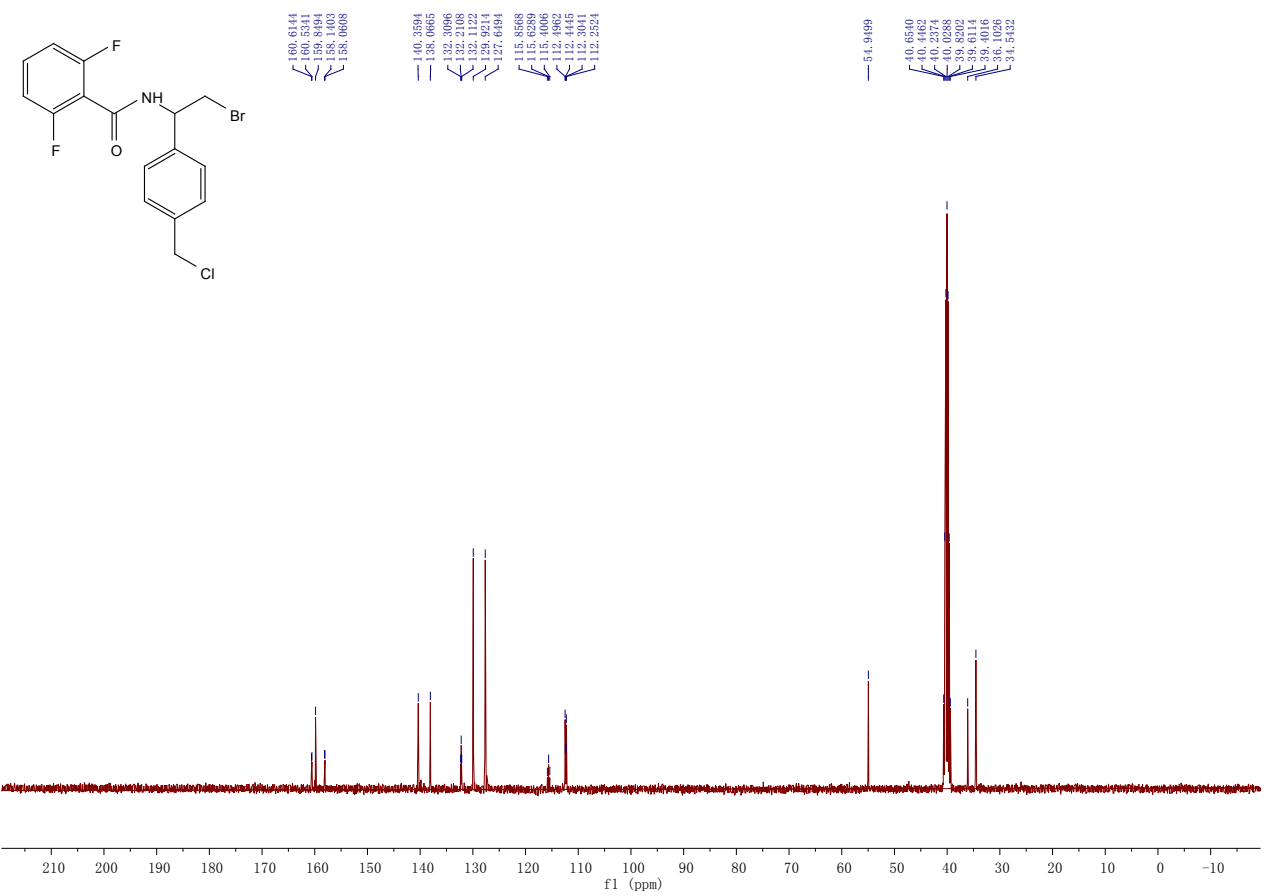

${ }^{13} \mathrm{C}$ NMR of Compound $4 \mathrm{c}$ 

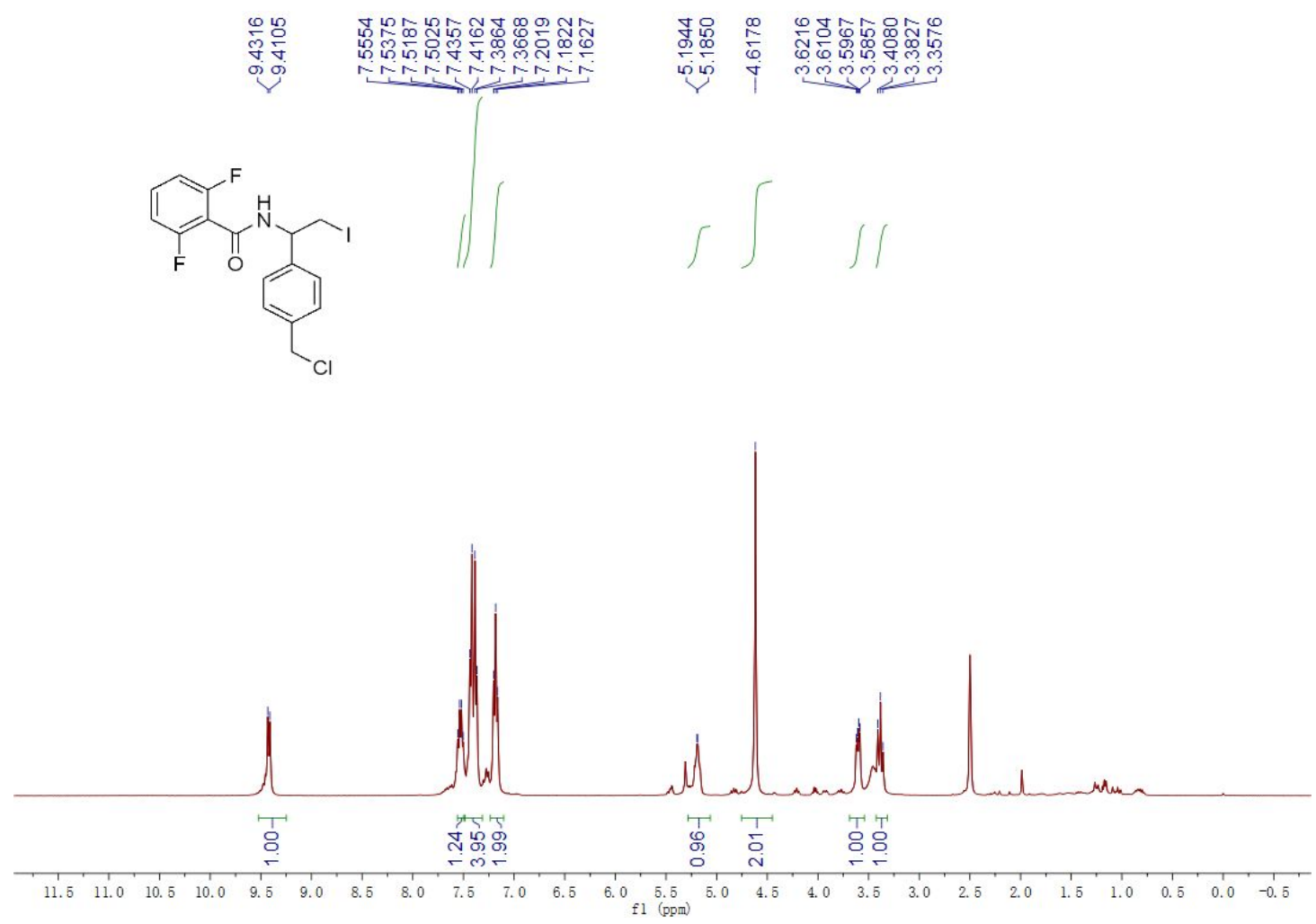

${ }^{1} \mathrm{H}$ NMR of Compound $\mathbf{4 d}$
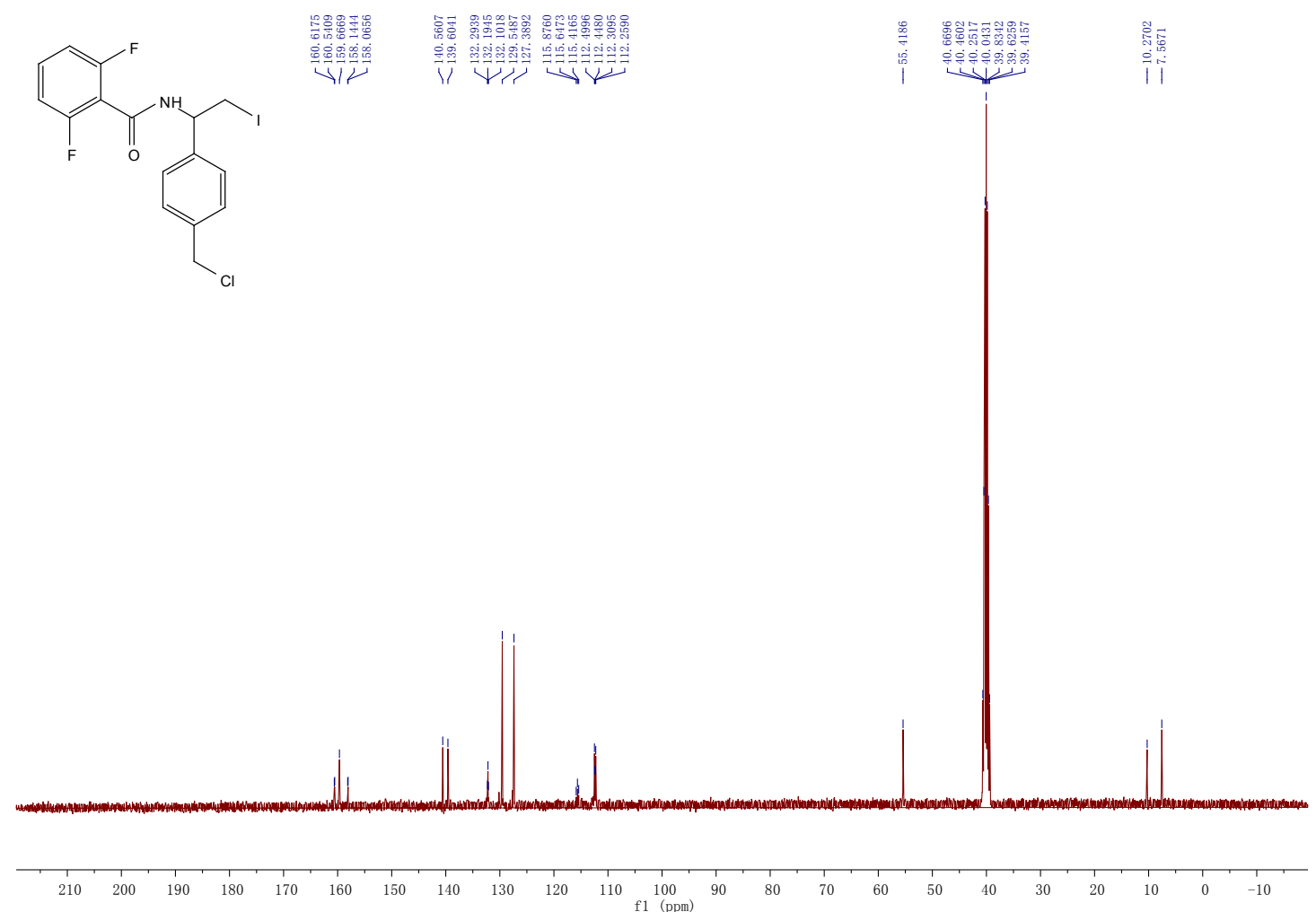

${ }^{13} \mathrm{C}$ NMR of Compound $4 \mathbf{d}$ 

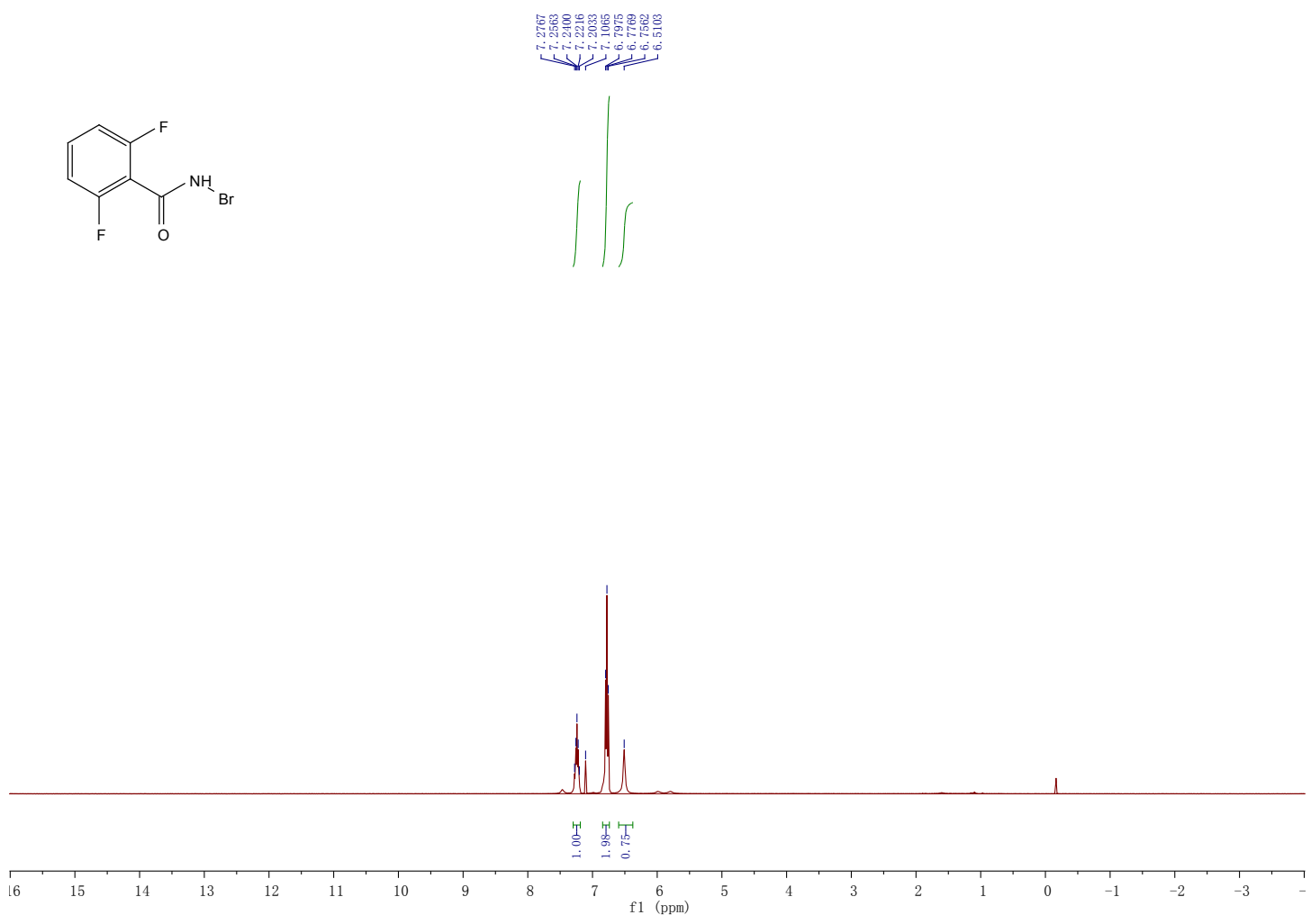

${ }^{1} \mathrm{H}$ NMR of Compound 15
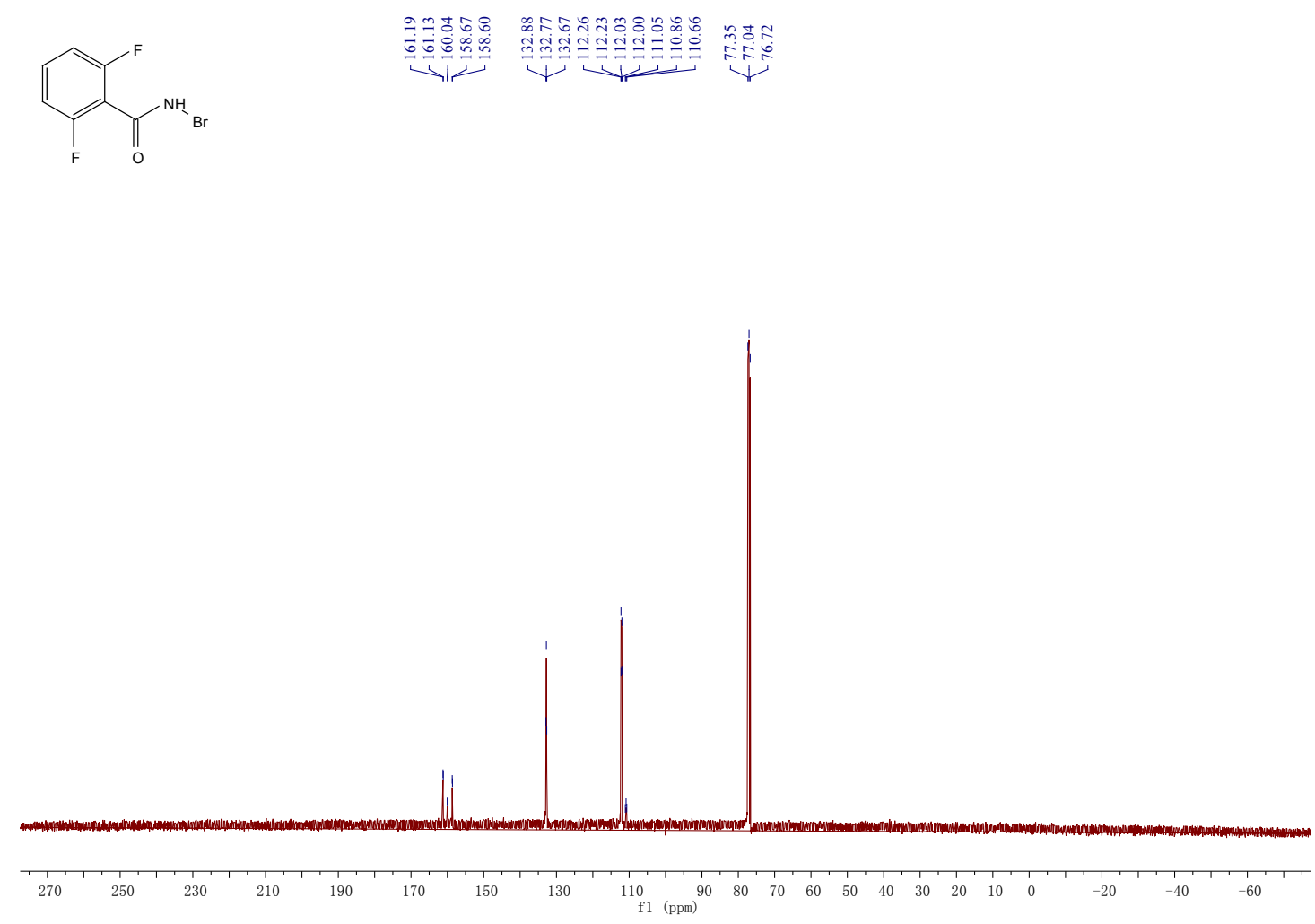

${ }^{13} \mathrm{C}$ NMR of Compound 15

9 

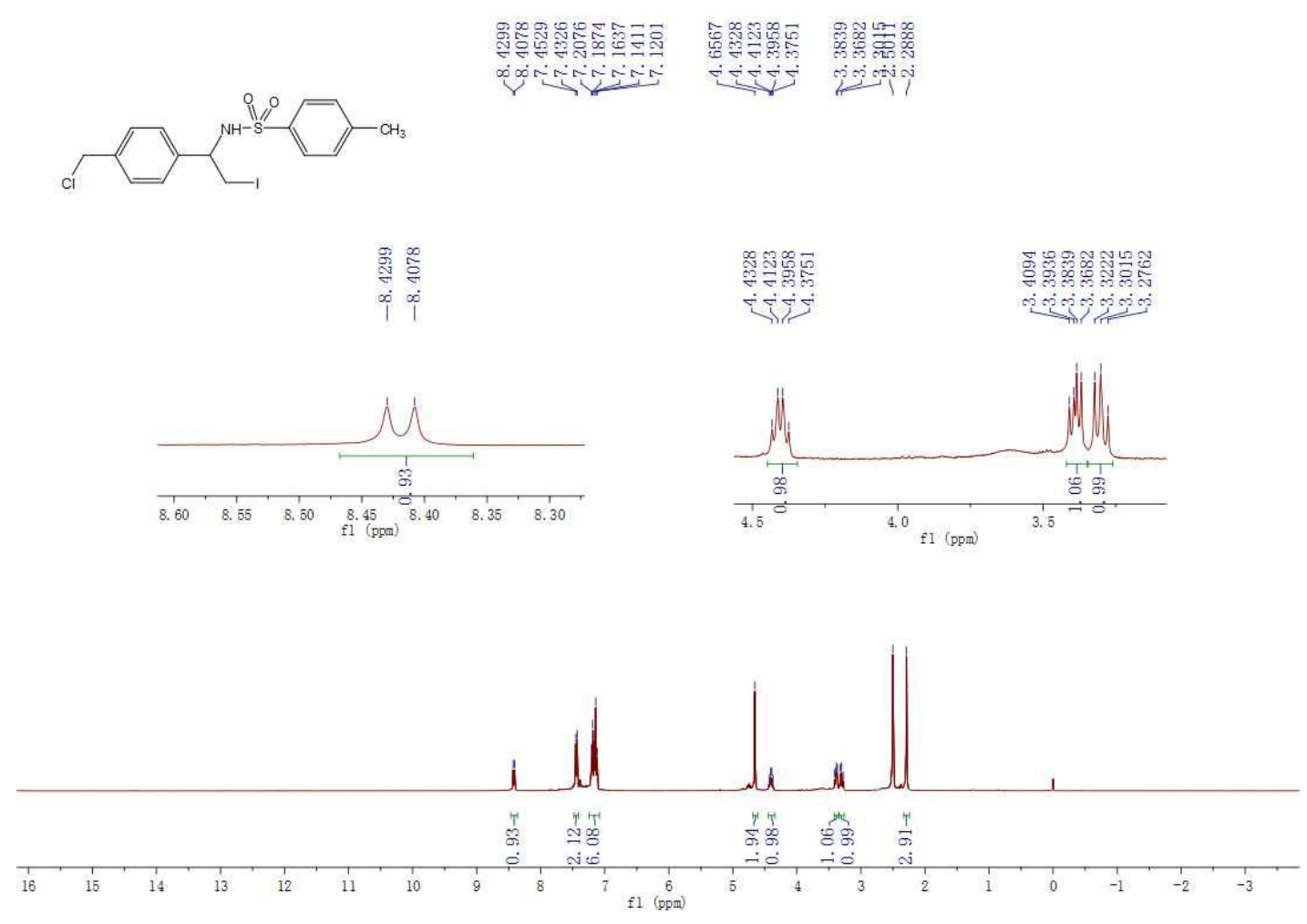

${ }^{1} \mathrm{H}$ NMR of Compound 17
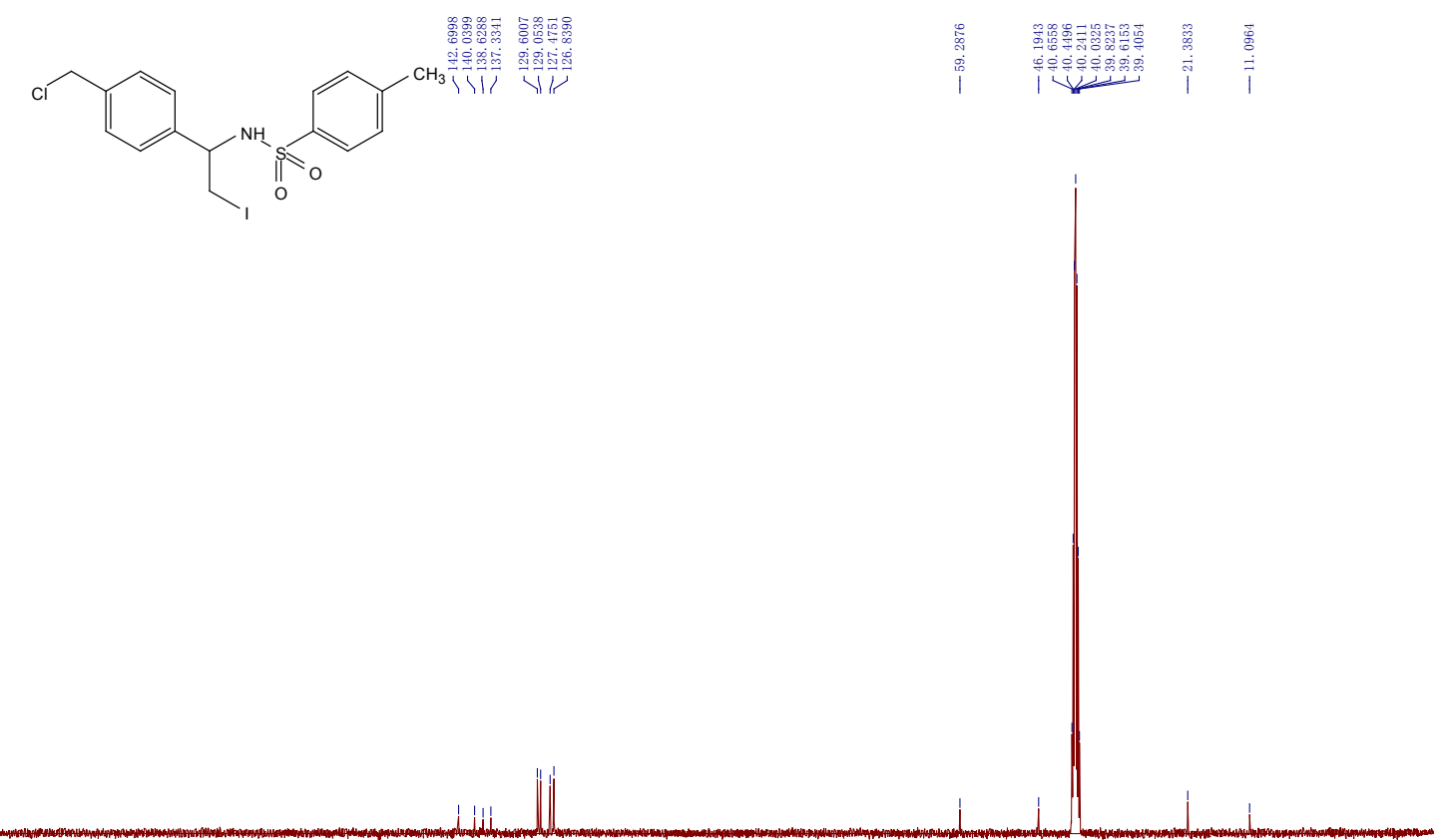

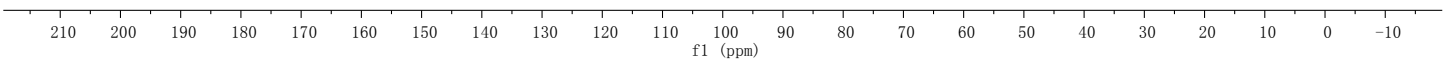

${ }^{13} \mathrm{C}$ NMR of Compound 17 


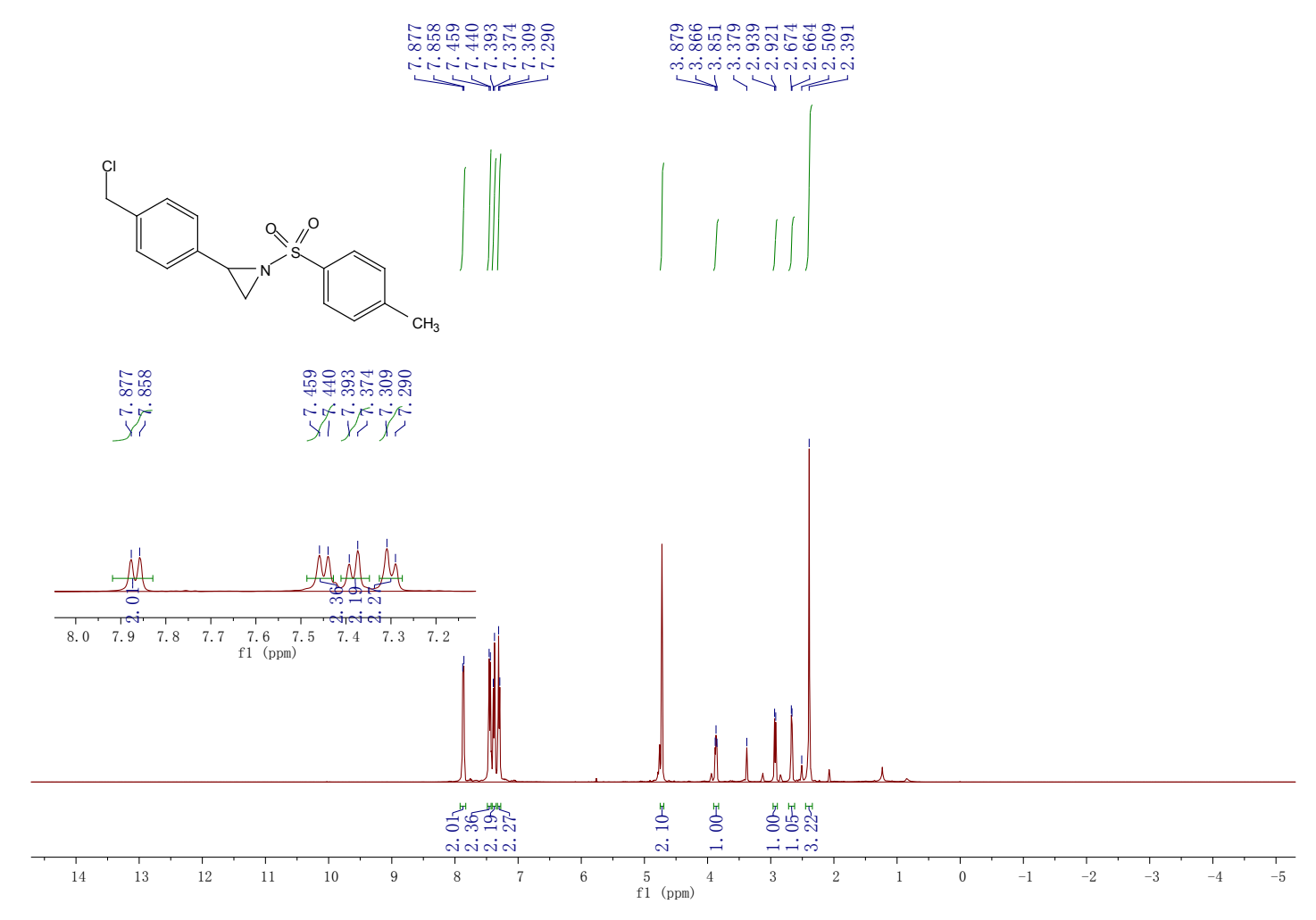

${ }^{1} \mathrm{H}$ NMR of Compound 19 

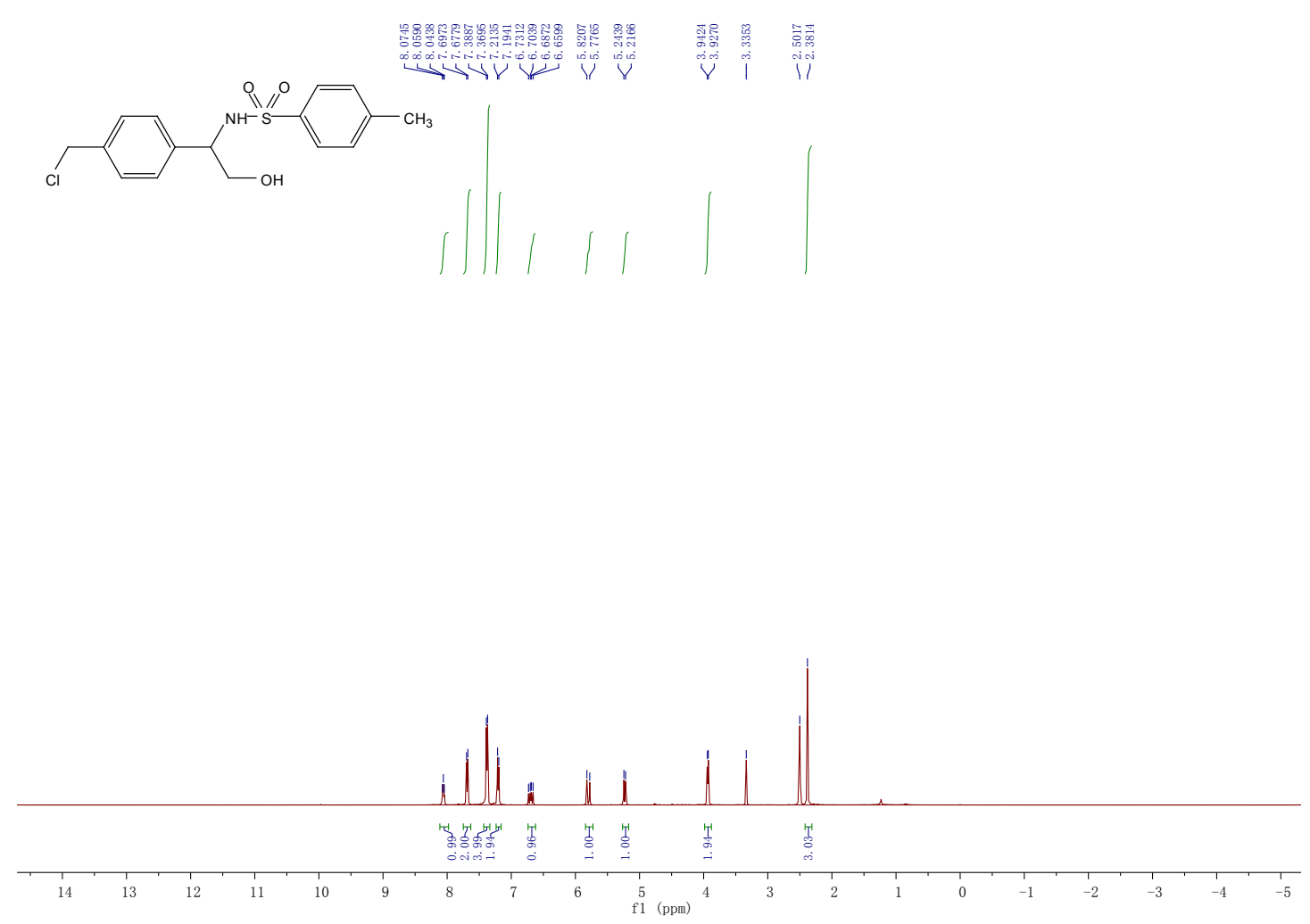

${ }^{1} \mathrm{H}$ NMR of Compound 20
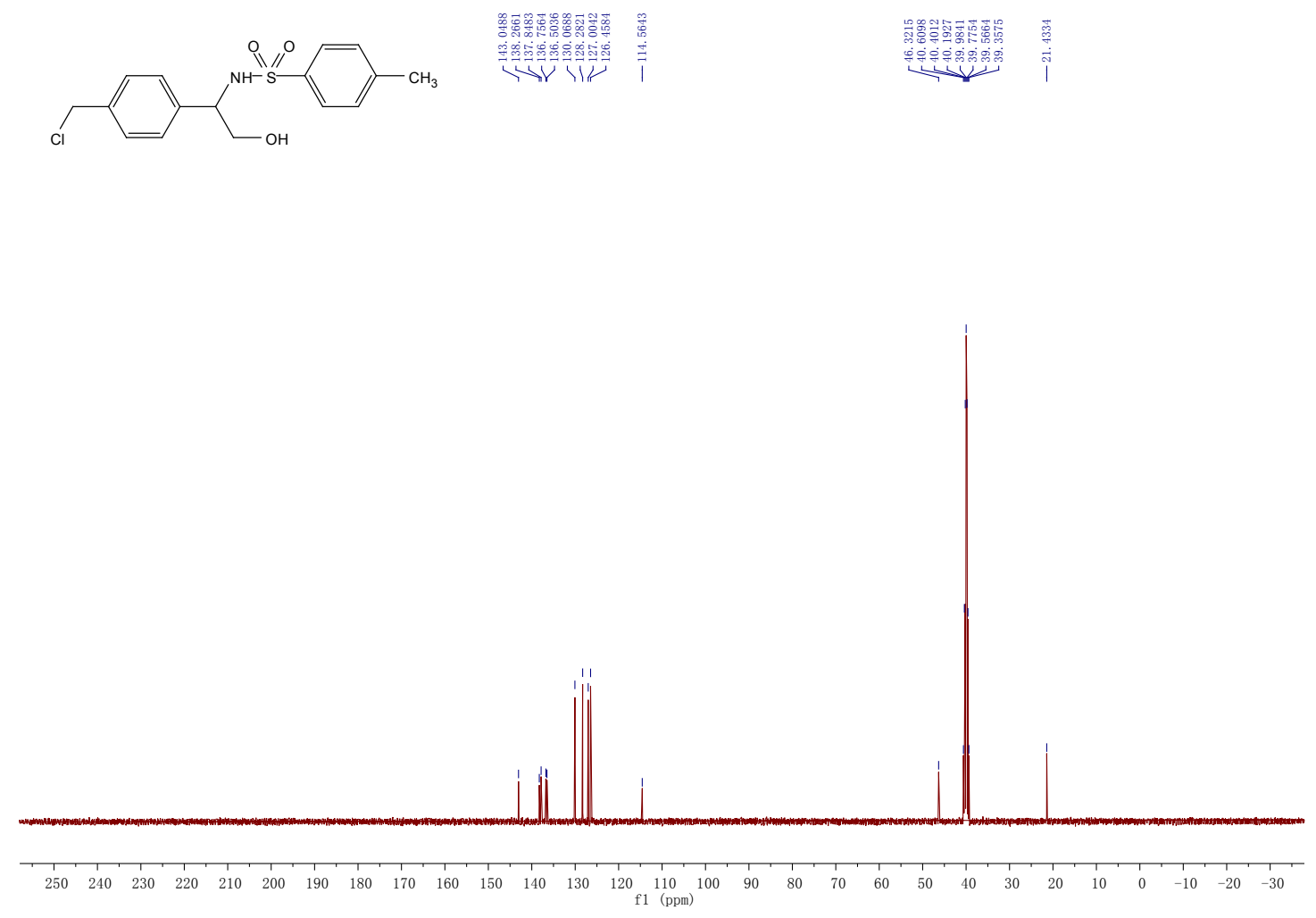

${ }^{13} \mathrm{C}$ NMR of Compound 20 


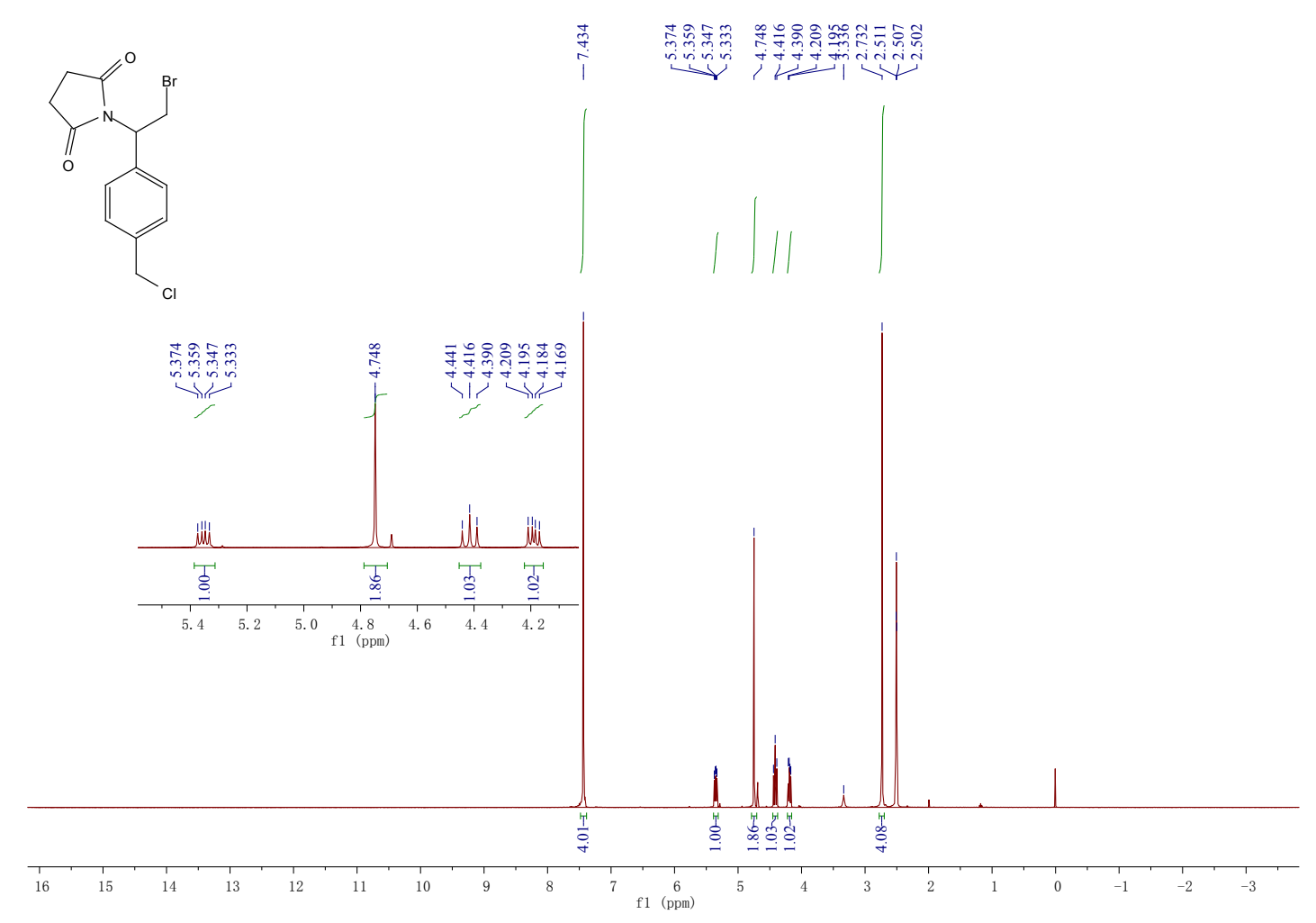

${ }^{1} \mathrm{H}$ NMR of Compound $\mathbf{2 3}$

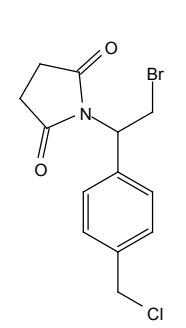

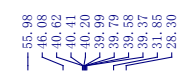

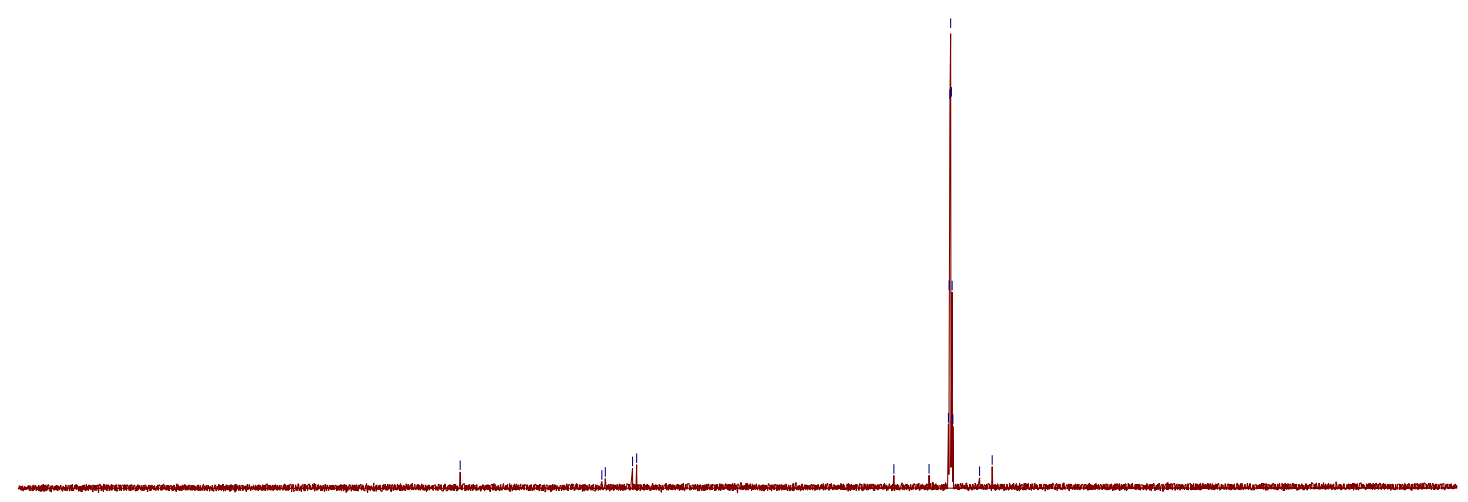

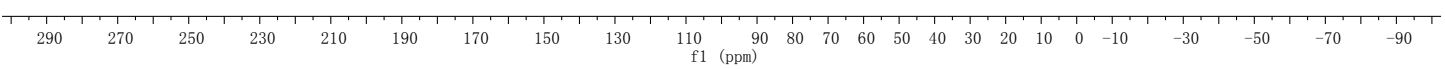

${ }^{13} \mathrm{C}$ NMR of Compound 23 


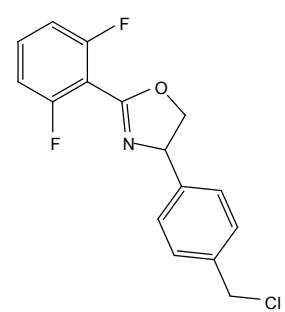

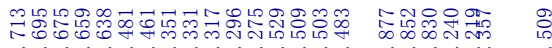

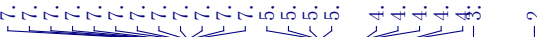

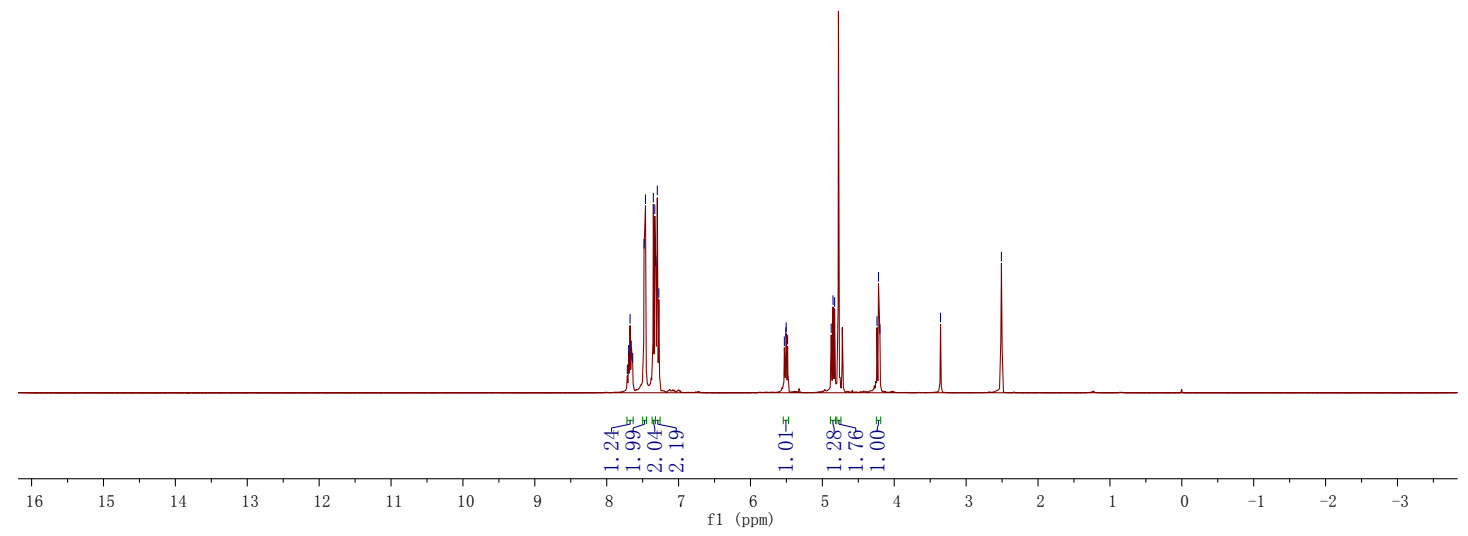

${ }^{1} \mathrm{H}$ NMR of Compound $\mathbf{5 b}$

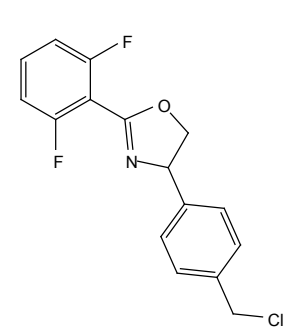

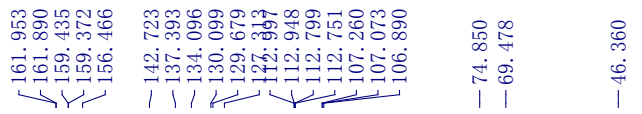

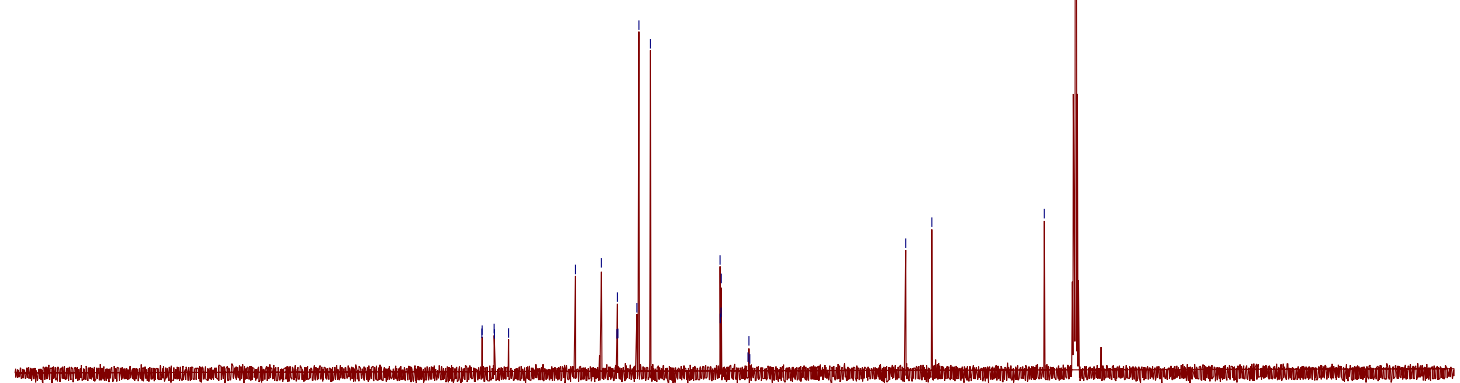

$\begin{array}{llllllllllllllllllllllllllllllll}250 & 240 & 230 & 220 & 210 & 200 & 190 & 180 & 170 & 160 & 150 & 140 & 130 & 120 & 110 & 100 & 90 & 80 & 1 & 60 & 50 & 40 & 30 & 20 & 10 & 0 & -10 & -20 & -30\end{array}$

${ }^{13} \mathrm{C}$ NMR of Compound $\mathbf{5 b}$ 

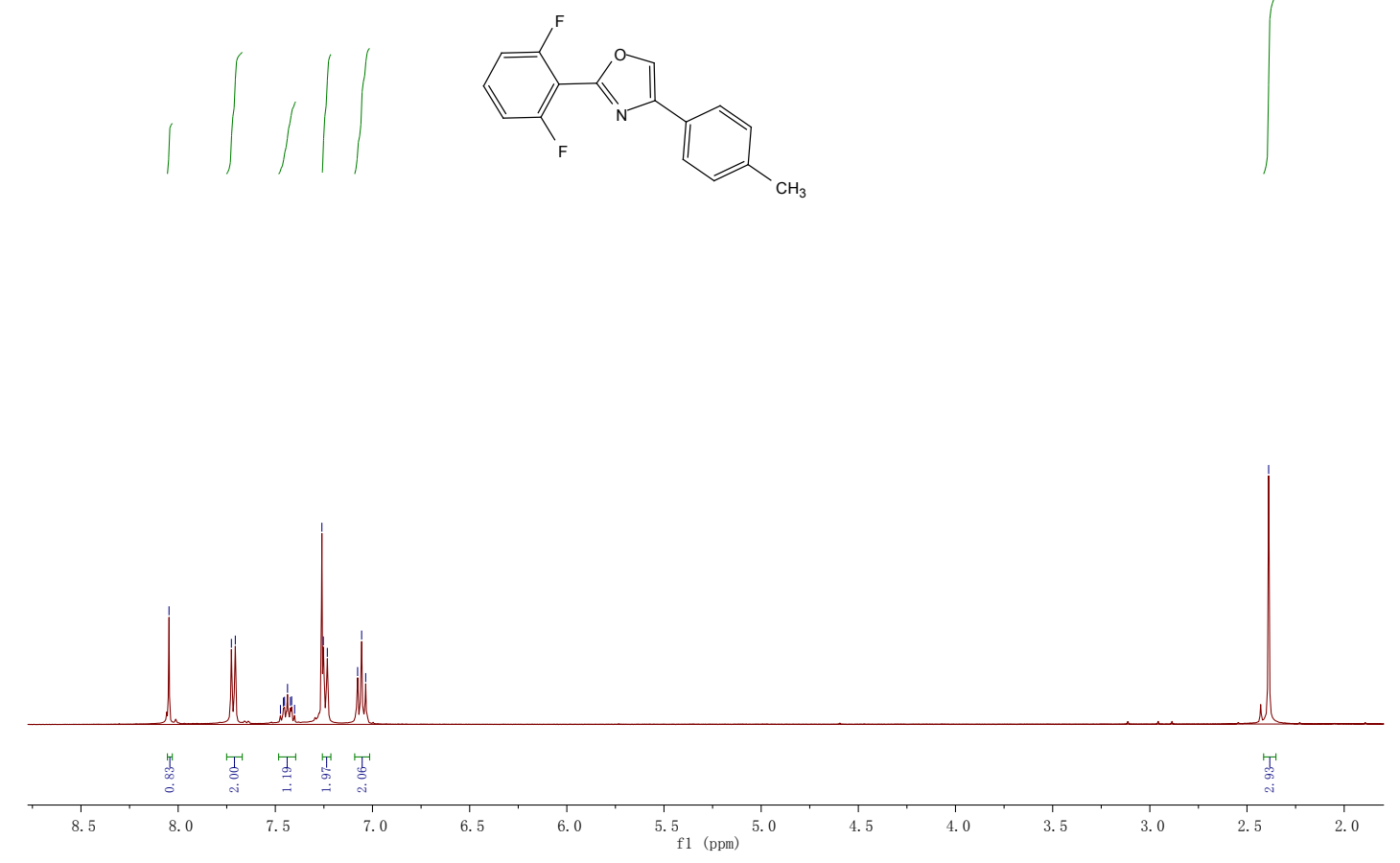

${ }^{1} \mathrm{H}$ NMR of Compound 27

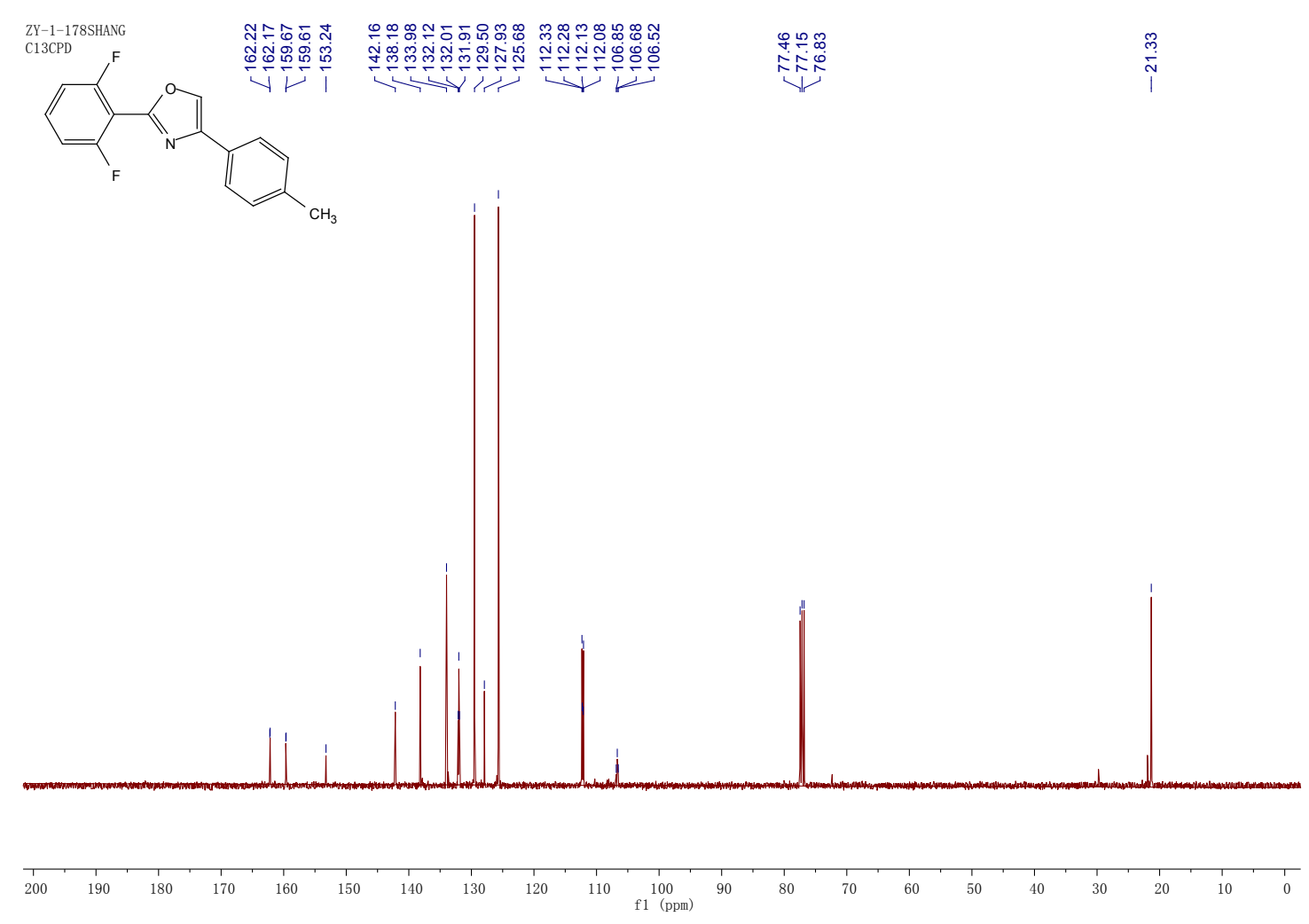

${ }^{13} \mathrm{C}$ NMR of Compound 27 


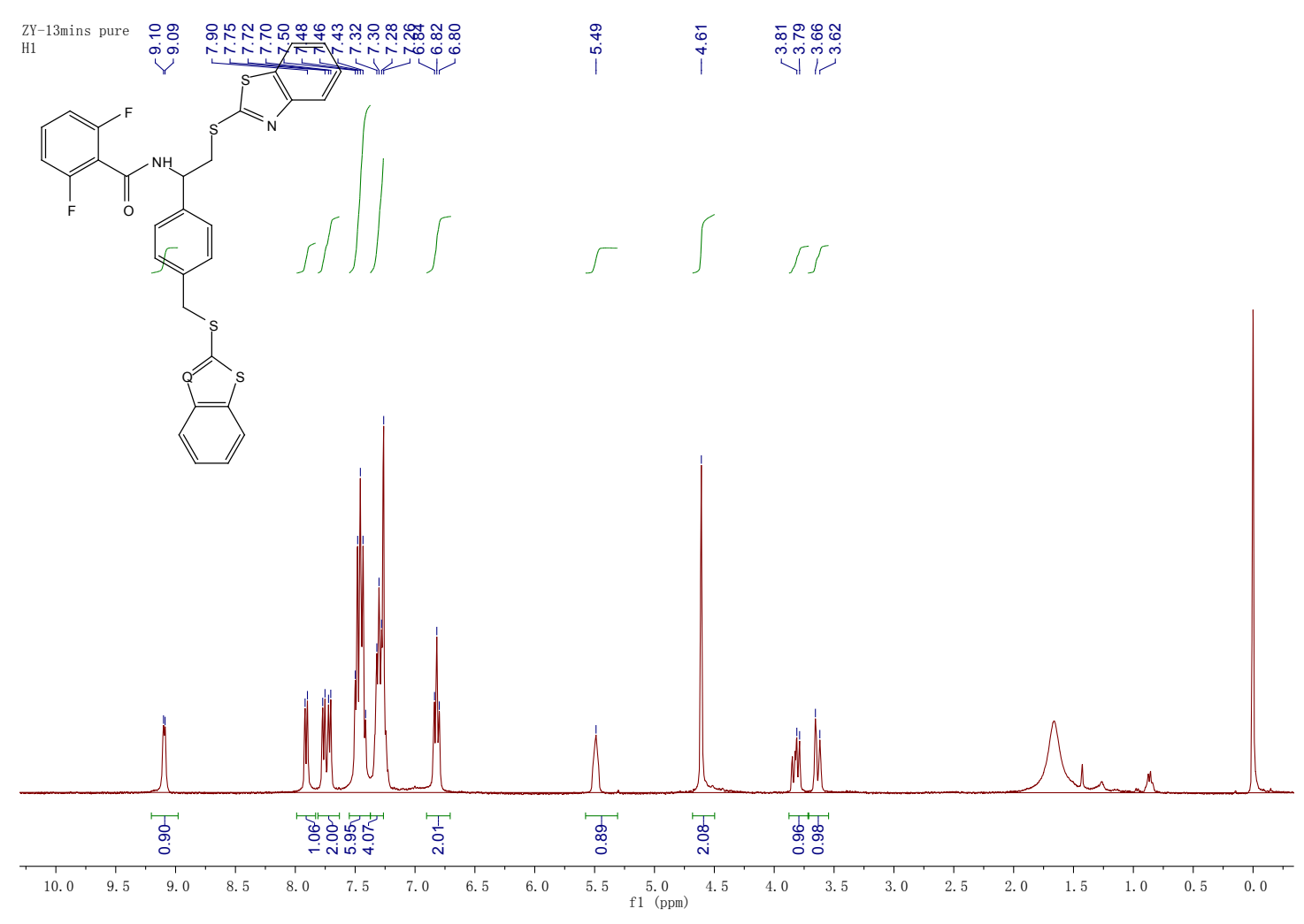

${ }^{1} \mathrm{H}$ NMR of Compound 28
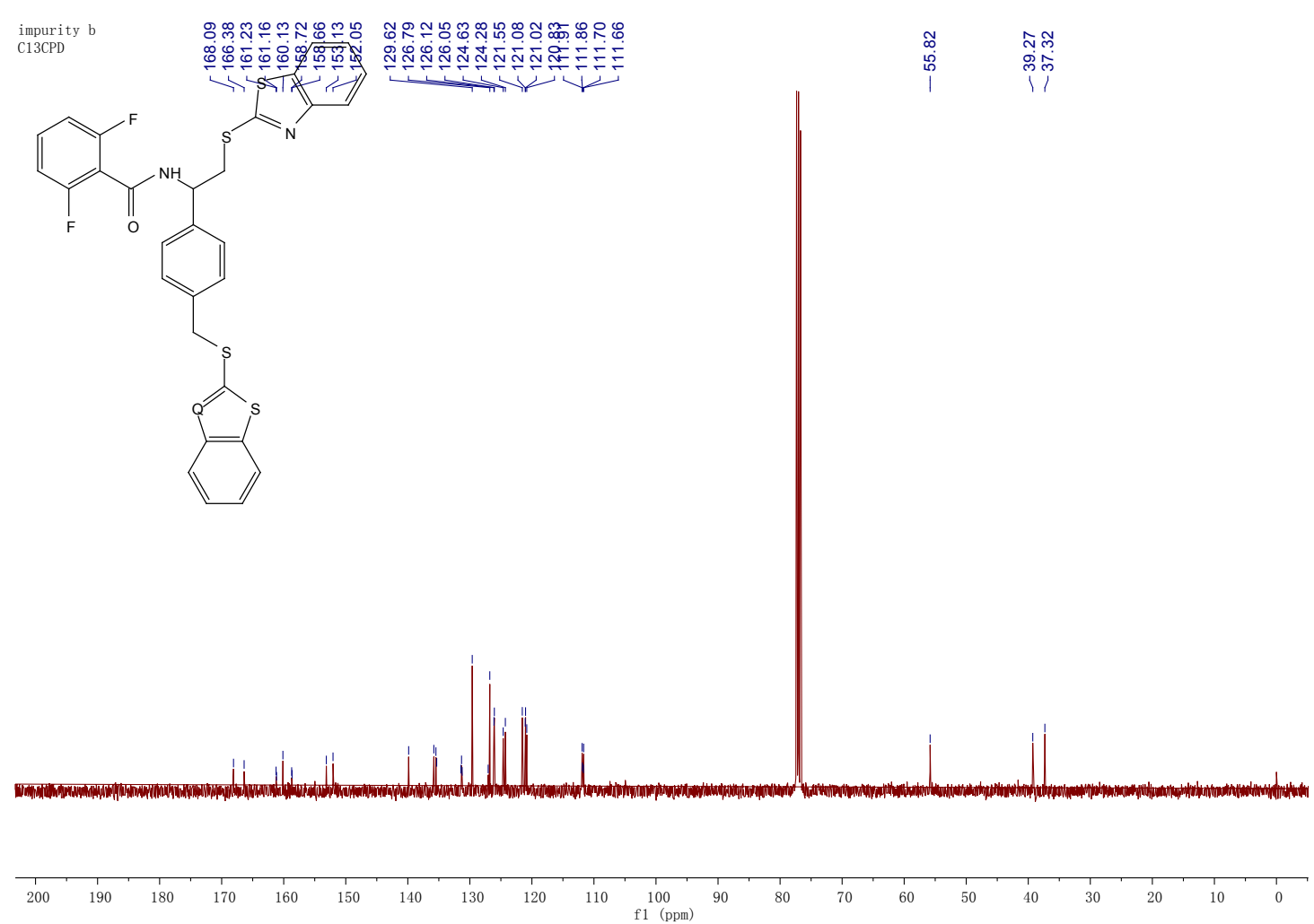

${ }^{13} \mathrm{C}$ NMR of Compound 28 


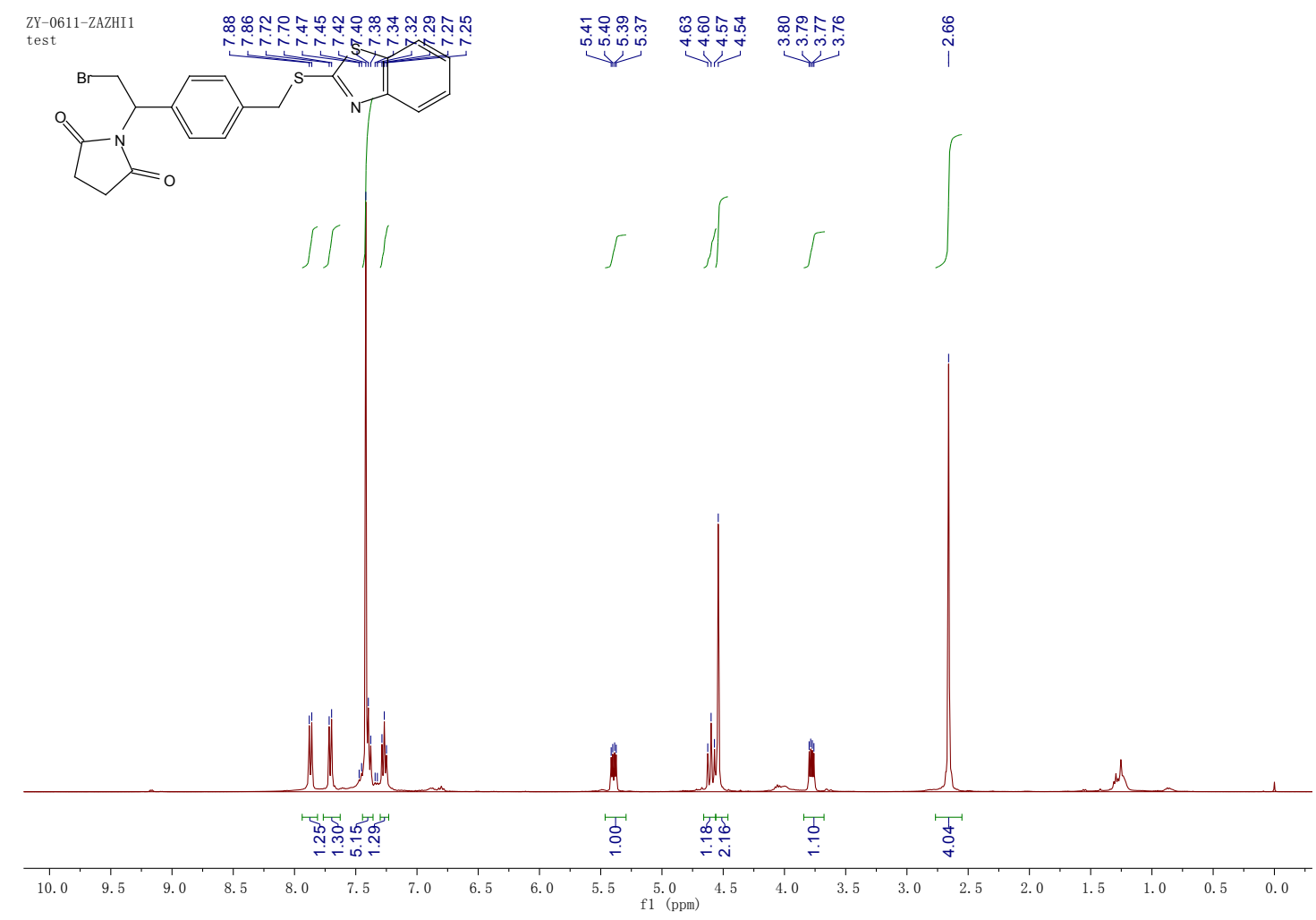

${ }^{1} \mathrm{H}$ NMR of Compound 29
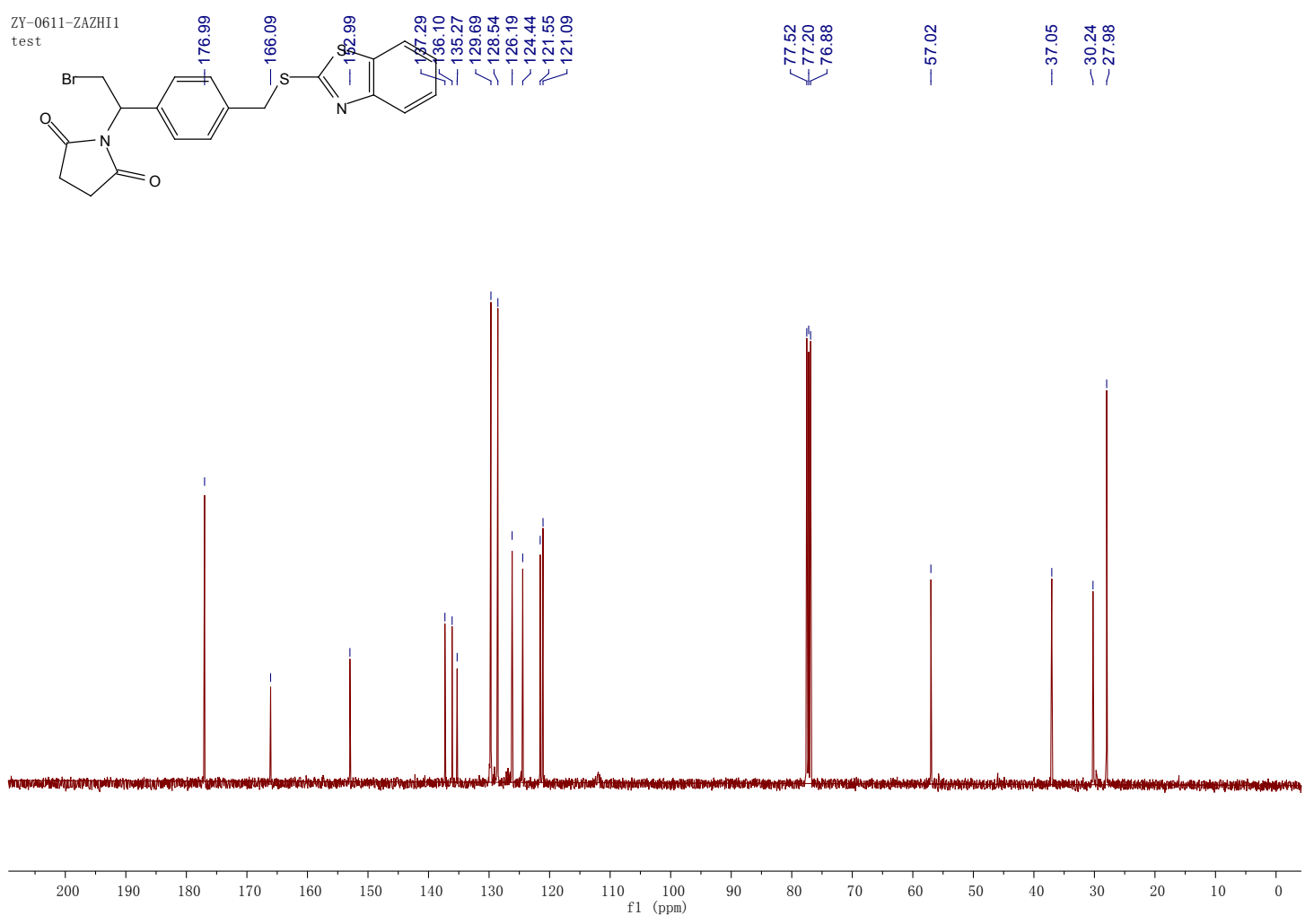

${ }^{13} \mathrm{C}$ NMR of Compound 29 


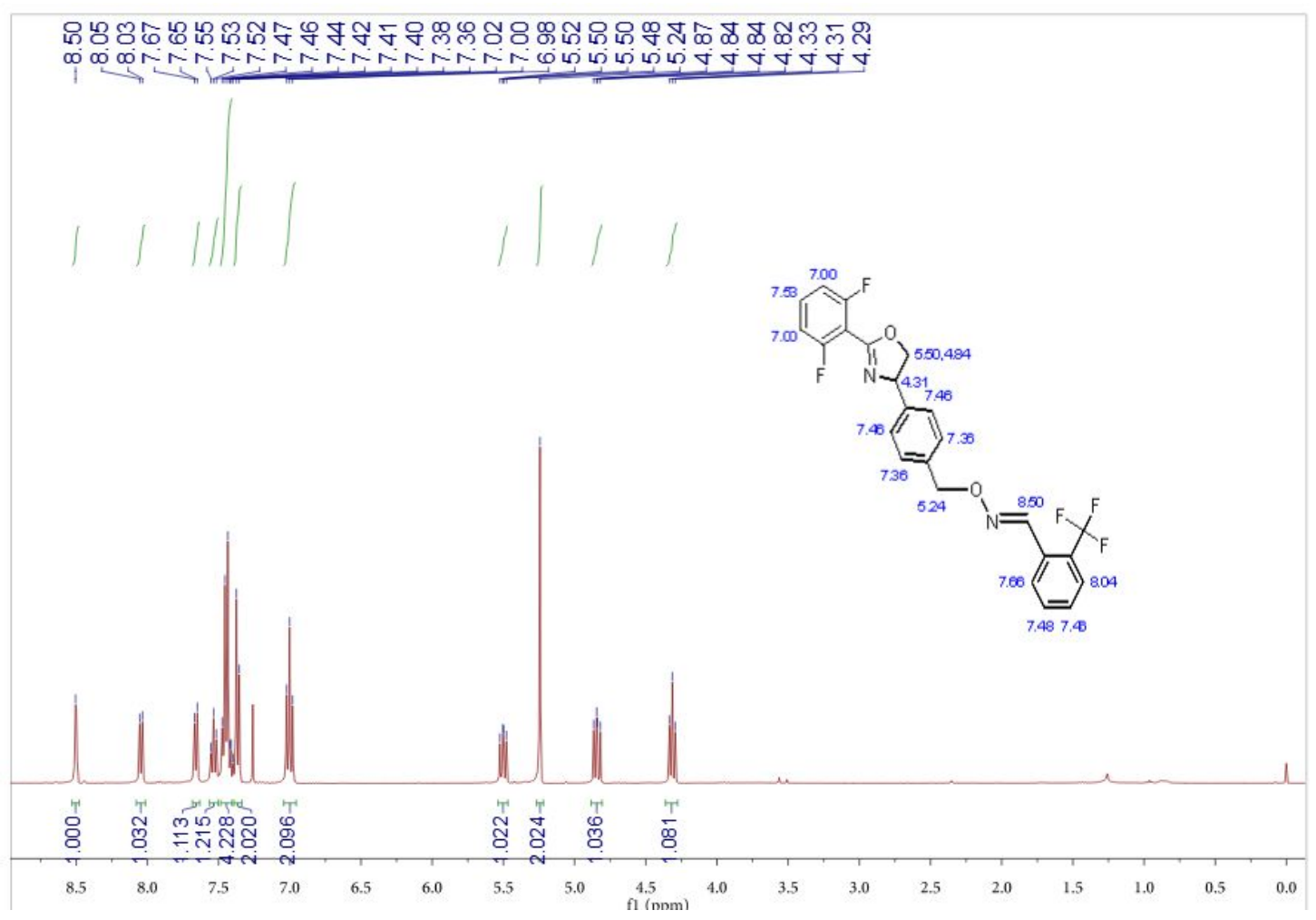

${ }^{1} \mathrm{H}$ NMR of Compound $\mathbf{1}$

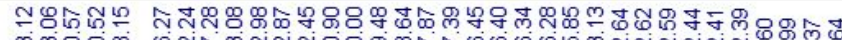 \\ ๒으유.}

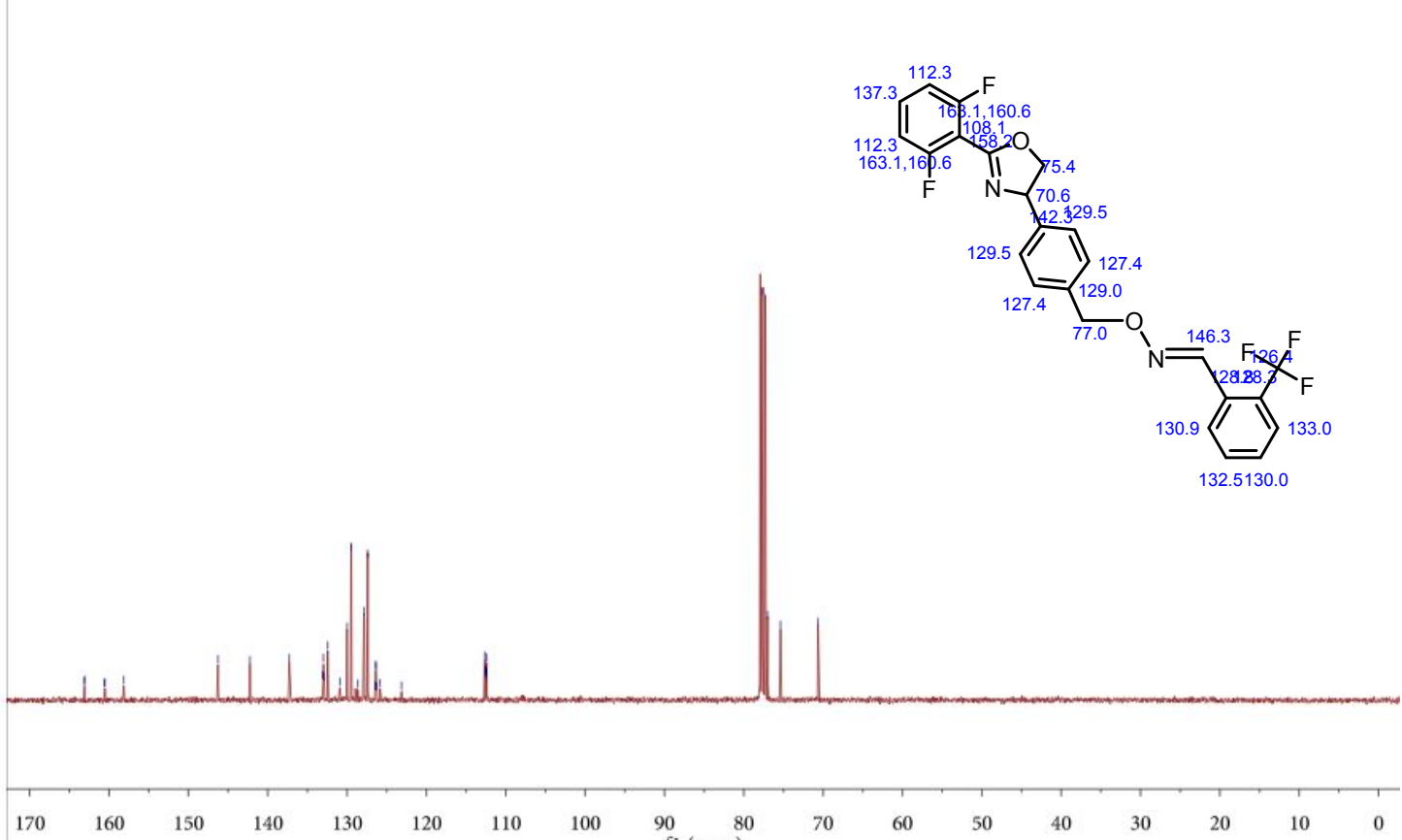

${ }^{13} \mathrm{C}$ NMR of Compound 1 


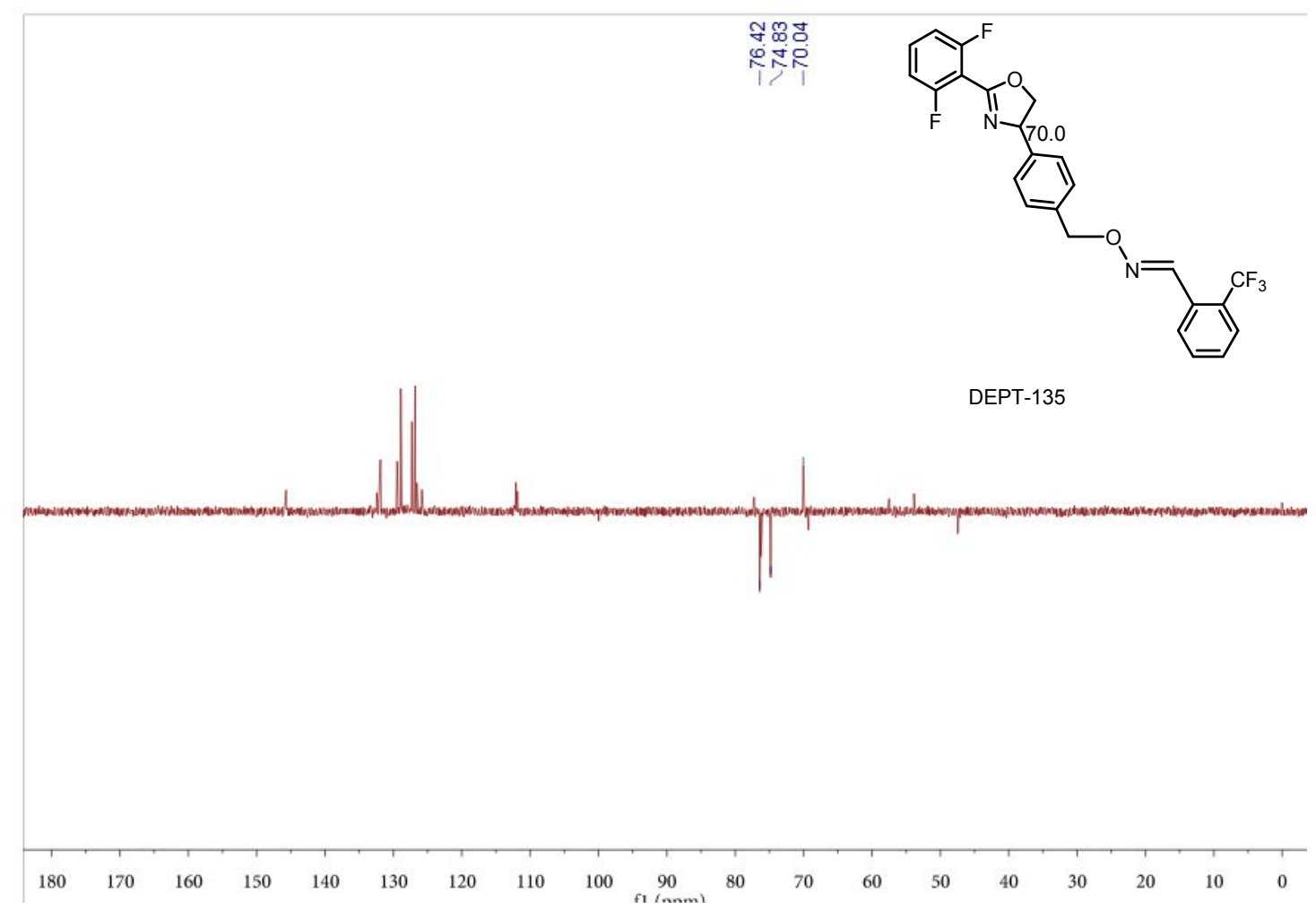

DEPT-135 of Compound 1

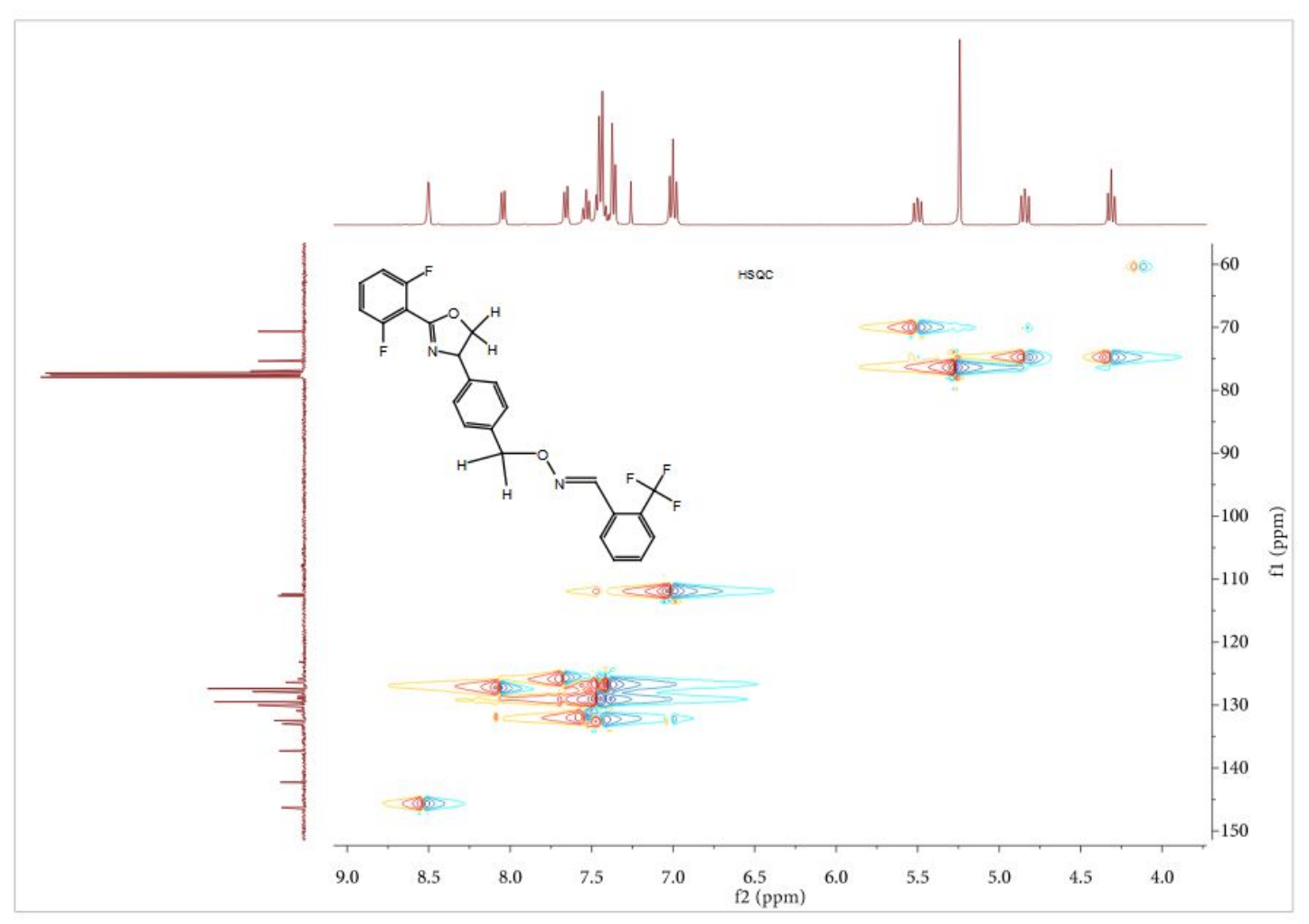

HSQC of Compound $\mathbf{1}$ 


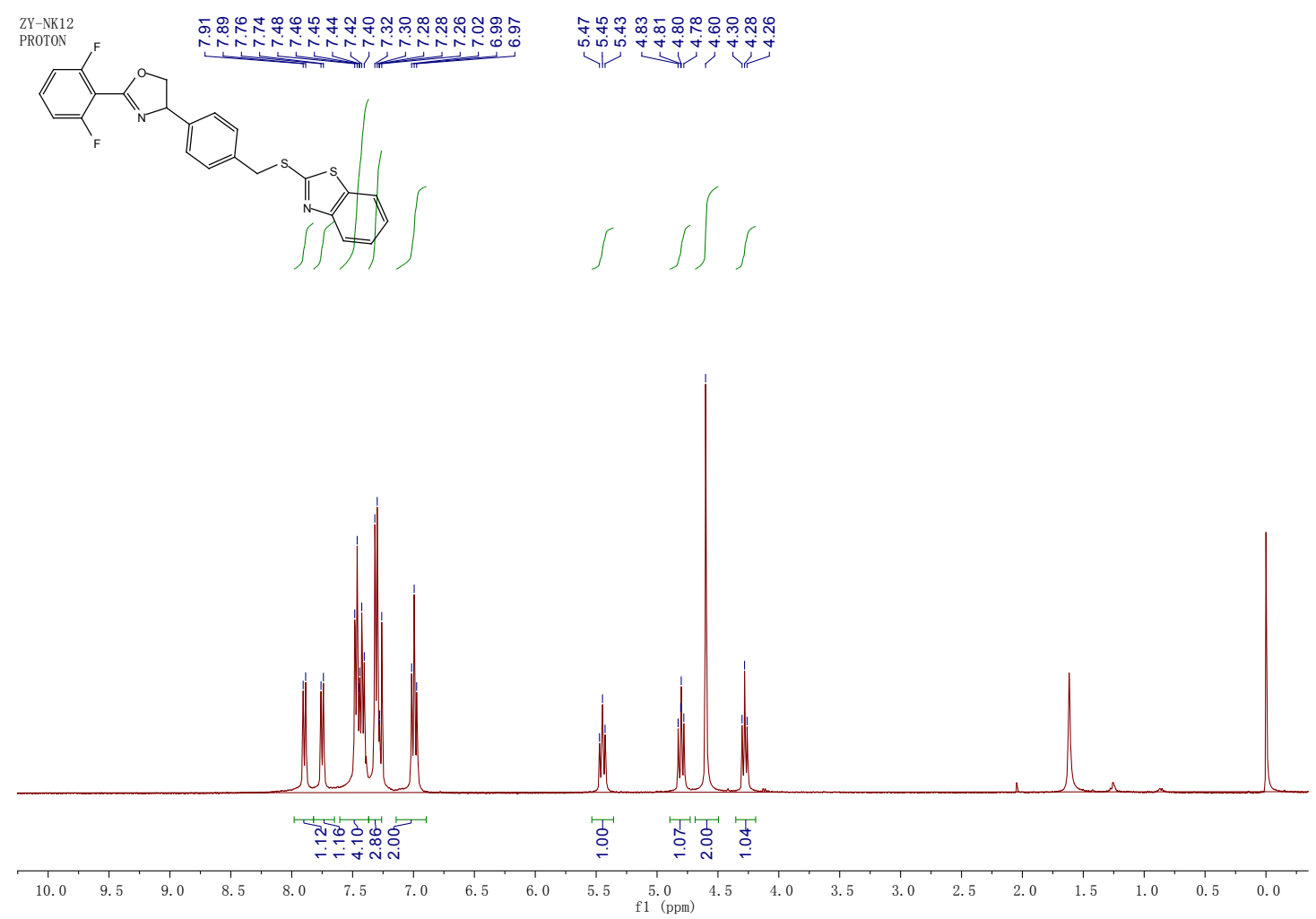

${ }^{1} \mathrm{H}$ NMR of Compound $\mathbf{2}$

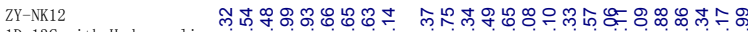

ID $13 \mathrm{C}$ with H decoupling

र당

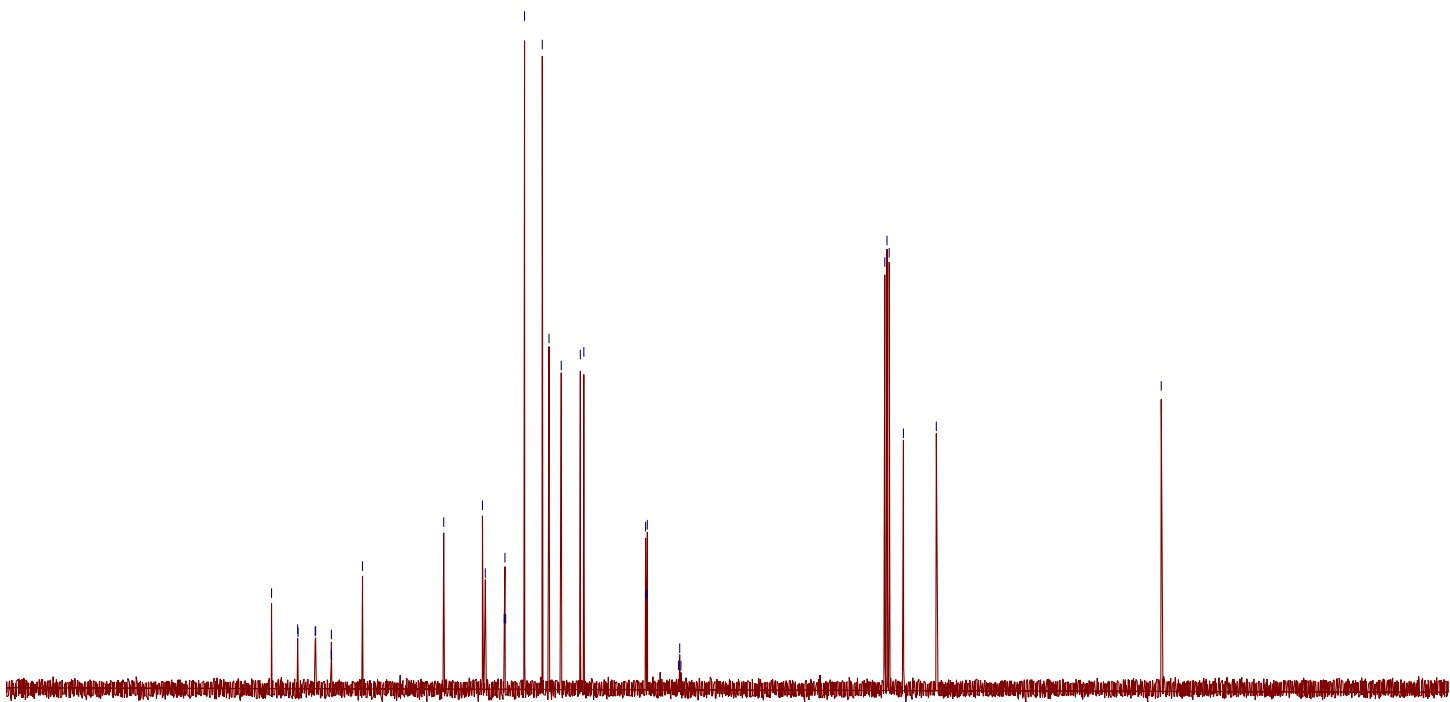

$\begin{array}{lllllll}200 & 190 & 180 & 170 & 160 & 150 & 140\end{array}$

$110 \underset{\mathrm{f} 1}{100}(\mathrm{ppm})$

80

$\begin{array}{lllllll}60 & 50 & 40 & 30 & 20 & 10 & 0\end{array}$

${ }^{13} \mathrm{C}$ NMR of Compound 2 


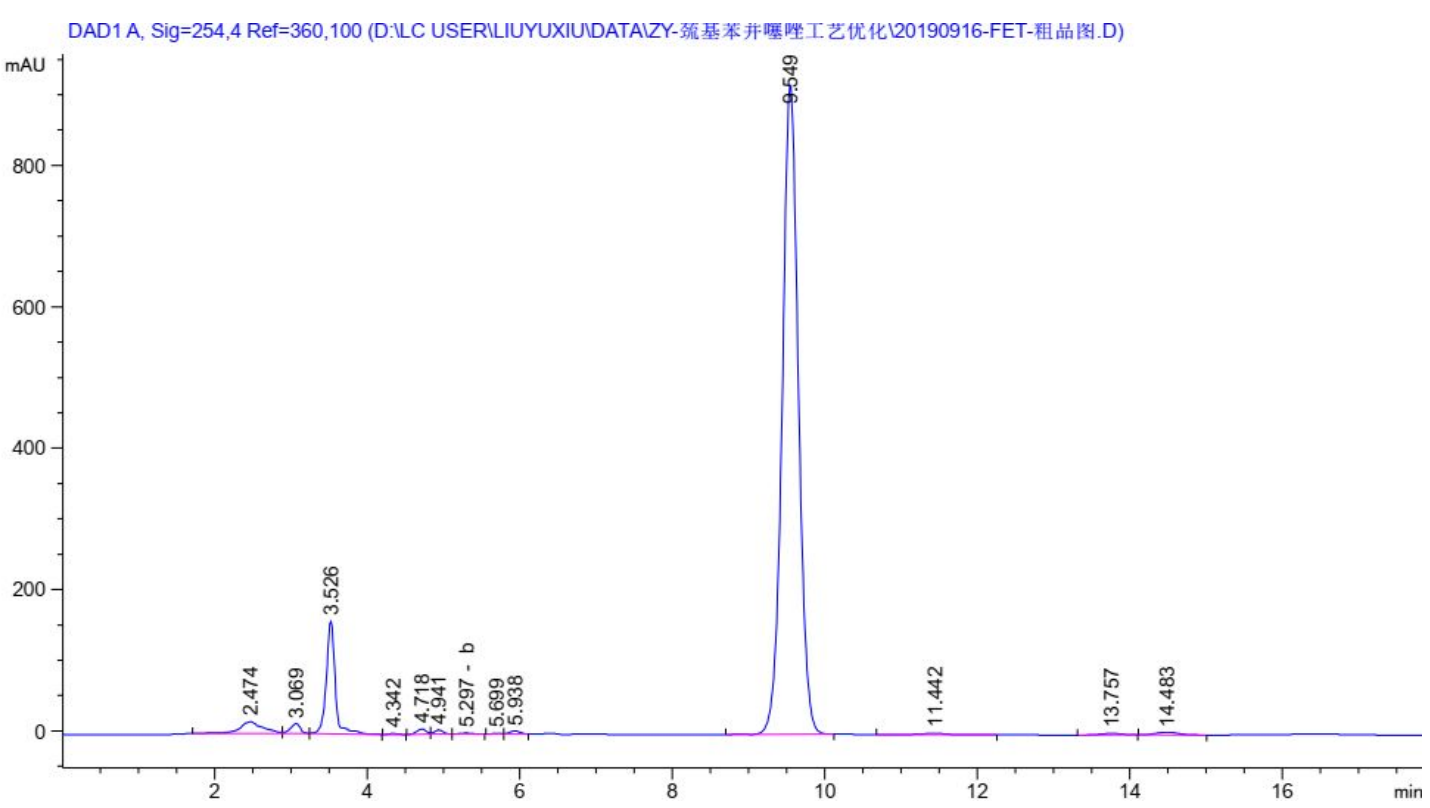

\section{HPLC spectrum of crude 1}

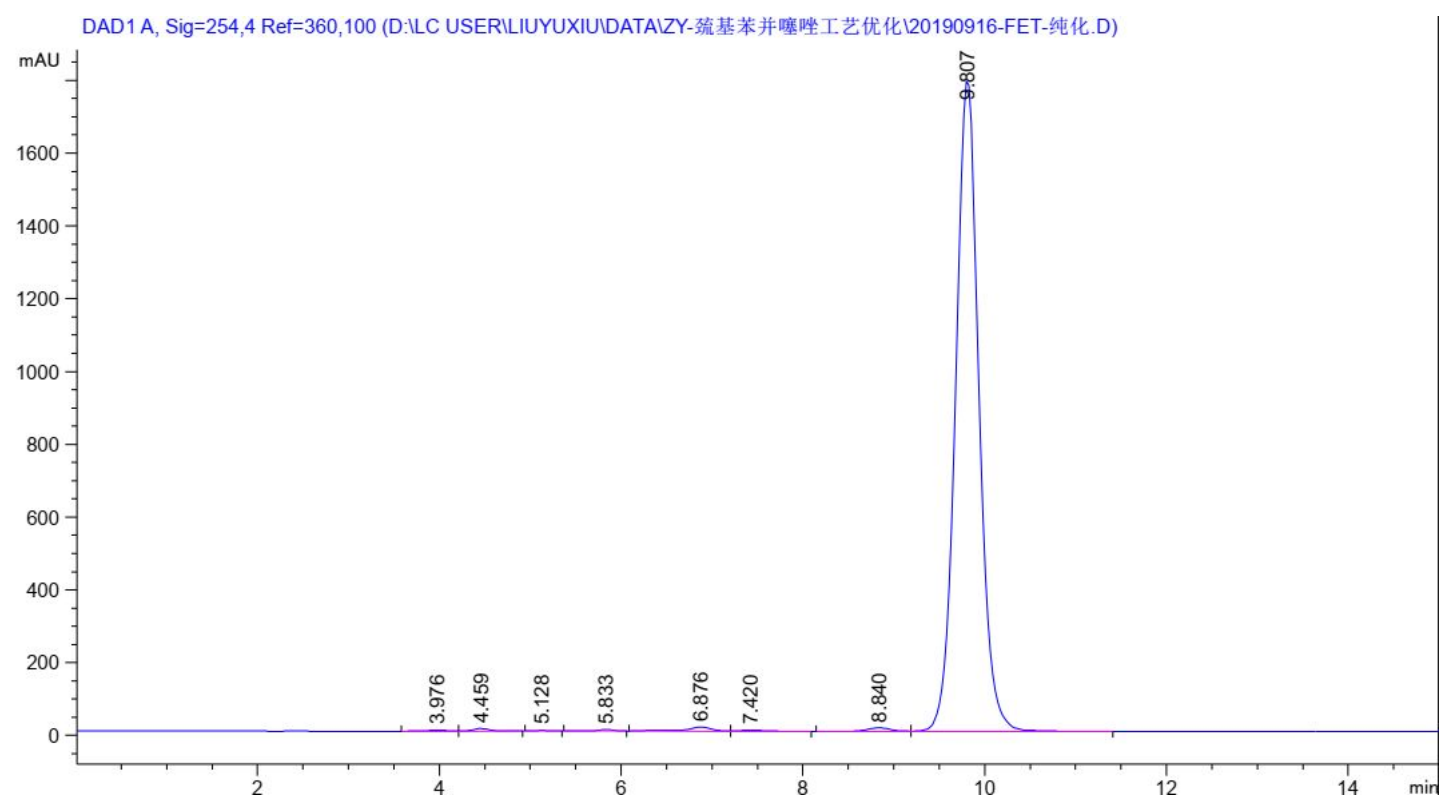

HPLC spectrum of pure $\mathbf{1}$ 


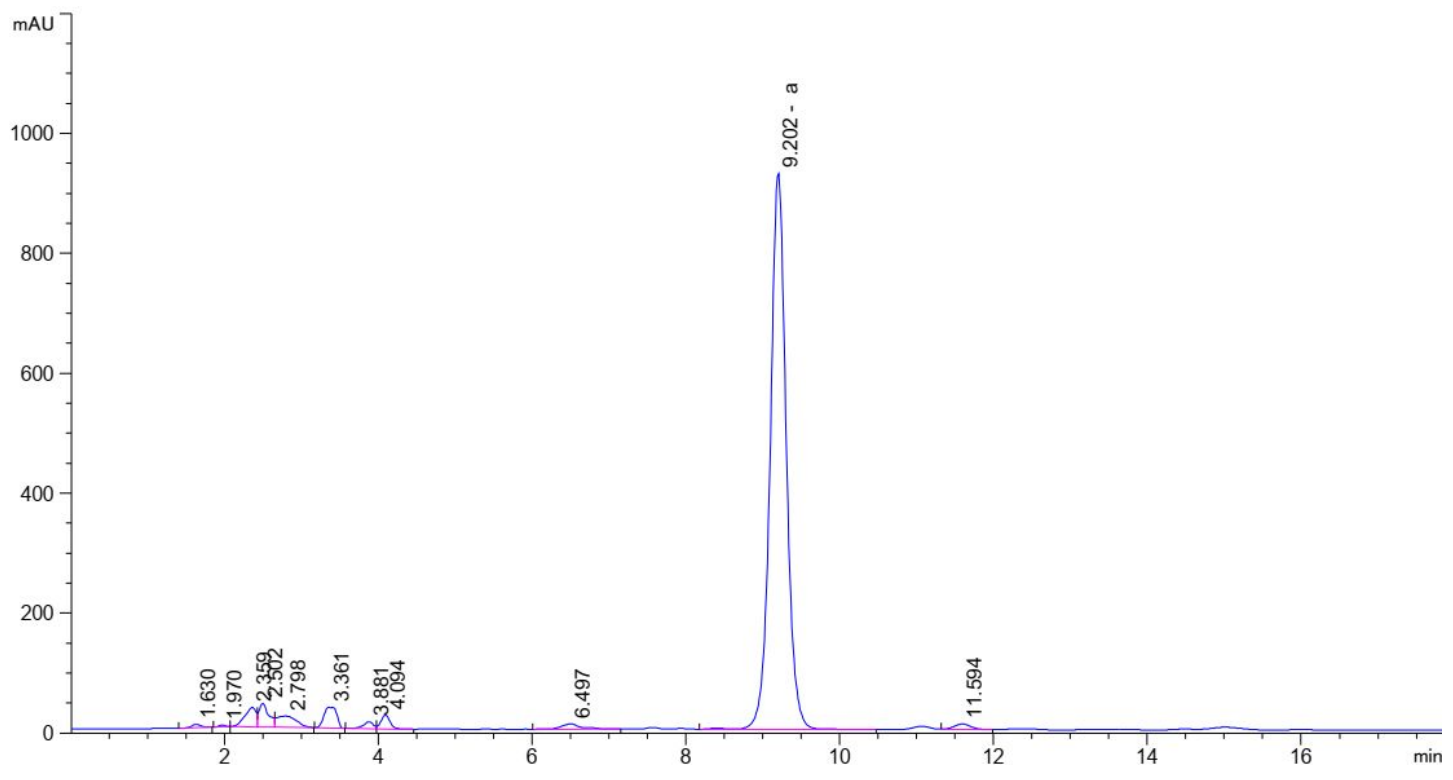

HPLC spectrum of crude 2

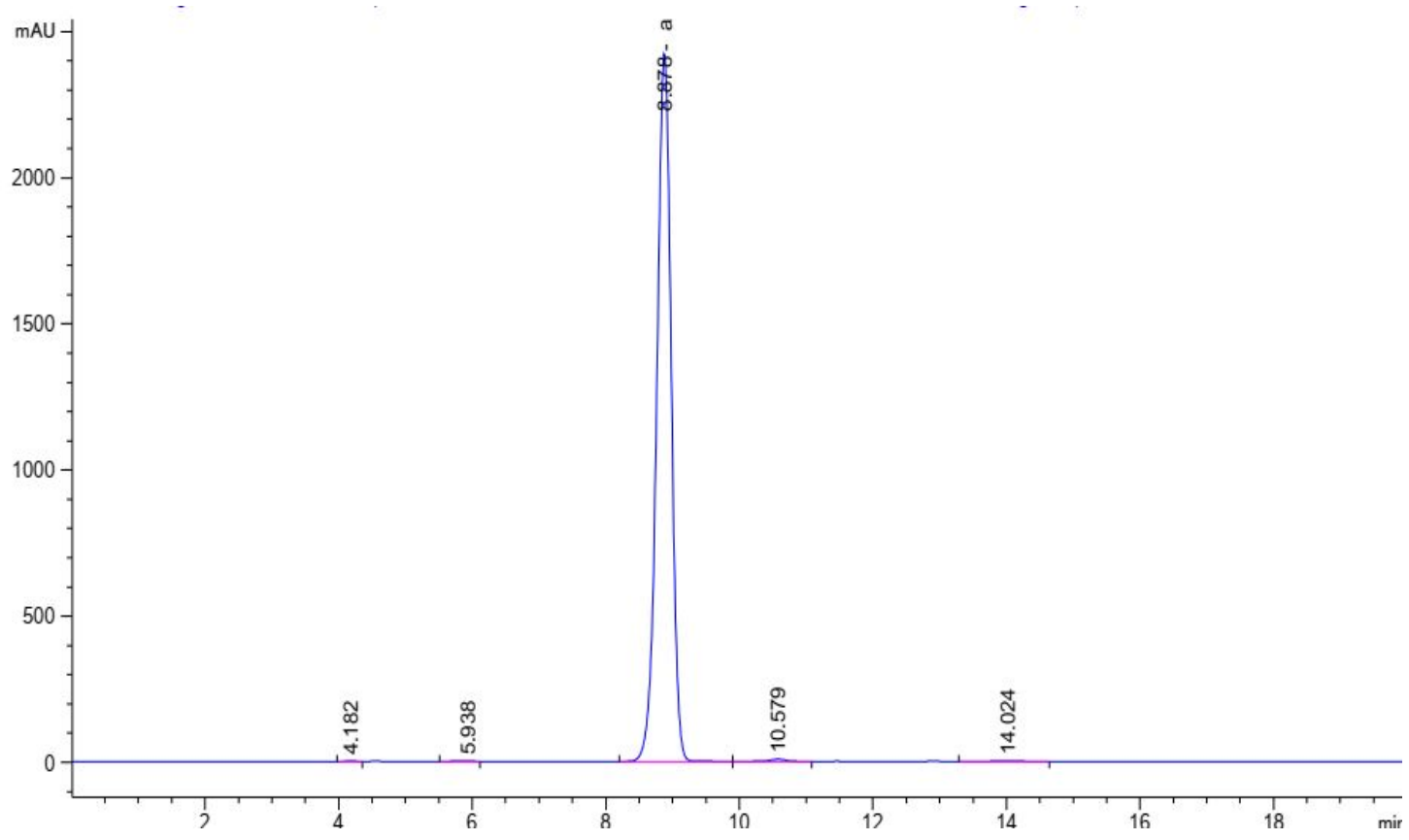

HPLC spectrum of pure 2 